\title{
Resistance to Turnip Mosaic Virus in the Family Brassicaceae
}

\author{
Peter Palukaitis (1D ${ }^{1 *}$ and Su Kim ${ }^{2 *}$ \\ ${ }^{1}$ Department of Horticultural Sciences, Seoul Women's University, Seoul 01797, Korea \\ ${ }^{2}$ Institute of Plant Analysis Technology Development, The Saeron Co., Suwon 16648, Korea \\ (Received on September 15, 2020; Revised on November 30, 2020; Accepted on November 30, 2020)
}

Resistance to diseases caused by turnip mosaic virus (TuMV) in crop species of the family Brassicaceae has been studied extensively, especially in members of the genus Brassica. The variation in response observed on resistant and susceptible plants inoculated with different isolates of TuMV is due to a combination of the variation in the plant resistome and the variation in the virus genome. Here, we review the breadth of this variation, both at the level of variation in TuMV sequences, with one eye towards the phylogeny and evolution of the virus, and another eye towards the nature of the various responses observed in susceptible vs. different types of resistance responses. The analyses of the viral genomes allowed comparisons of pathotyped viruses on particular indicator hosts to produce clusters of host types, while the inclusion of phylogeny data and geographic location allowed the formation of the host/ geographic cluster groups, the derivation of both of which are presented here. Various studies on resistance determination in particular brassica crops sometimes led to further genetic studies, in many cases to include the mapping of genes, and in some cases to the actual identification of the genes. In addition to summarizing

\footnotetext{
*Co-corresponding authors

P. Palukaitis

Phone) +82-2-970-5614, FAX) +82-2-970-5610

E-mail) peterp@swu.ac.kr

S. Kim

Phone) +82-31-5182-8112, FAX) +82-31-5182-8113

E-mail)gmsu25@gmail.com

ORCID

Peter Palukaitis

https://orcid.org/0000-0001-8735-1273

(c) This is an Open Access article distributed under the terms of the Creative Commons Attribution Non-Commercial License (http:// creativecommons.org/licenses/by-nc/4.0) which permits unrestricted noncommercial use, distribution, and reproduction in any medium, provided the original work is properly cited.
}

Articles can be freely viewed online at www.ppjonline.org. the results from such studies done in brassica crops, as well as in radish and Arabidopsis (the latter as a potential source of candidate genes for brassica and radish), we also summarize work done using nonconventional approaches to obtaining resistance to TuMV.

Keywords : brassica, plant resistance, radish, resistance genes, turnip mosaic virus

Handling Editor : Seung-Kook Choi

Genetic-based resistance to viruses is the most acceptable and durable form of crop protection, when it is available. This is particularly important for vegetable crops. This requires genetic resources for resistance (or tolerance), already available in some cultivars of various crops, or in wild relatives, which then can be crossed with the crop species. In a survey of the most important viruses infecting crops in the field, involving 28 countries and regions, turnip mosaic virus (TuMV) ranked as the second most important virus, after cucumber mosaic virus (CMV) (Tomlinson, 1987). The host range of TuMV includes at least 318 species in 156 genera, from 43 eudicotyledon families, including Brassicaceae (formerly Cruciferae), Asteraceae (formerly Compositae), Amaranthaceae (now including the former family Chenopodiaceae), Fabaceae (formerly Leguminosae), and Caryophyllaceae (Edwardson and Christie, 1991). In addition, some isolates can also infect species in at least seven monocotyledon families: Amaryllidaceae, Araceae, Commelinaceae, Iridaceae, Liliaceae, Musaceae, and Orchidaceae. TuMV can be transmitted by at least 89 species of aphid (Edwardson and Christie, 1986). Infection by TuMV is especially damaging to brassicid crops in parts of Europe, Asia and North America, with yield losses of up to $70 \%$ ( $\mathrm{Li}$ et al., 2019a). These crops include oilseed rape (aka canola; Brassica napus), swede (aka rutabaga; $B$. napus ssp. napobrassica; formerly B. napobrassica; aka $B$. 
napus ssp. rapifera), turnip (B. rapa ssp. rapa; formerly $B$. rapa ssp. campestris; aka $B$. rapa ssp. rapifera), Chinese cabbage ( $B$. rapa ssp. pekinensis; formerly $B$. pekinensis; aka $B$. campestris ssp. pekinensis), mizuna (B. rapa ssp. nipposinica), pak choy (aka bok choy, aka pok choy; $B$. rapa ssp. chinensis; formerly $B$. chinensis), choy sum ( $B$. rapa ssp. parachinensis; formerly $B$. parachinensis), broccoli (B. oleracea ssp. italica), Brussels sprout (B. oleracea ssp. gemmifera), cabbage (B. oleracea ssp. capita), cauliflower (B. oleracea ssp. botrytis), collard (B. oleracea var. acephala), kale (B. oleracea var. acephala), kohlrabi ( $B$. oleracea ssp. gongylodes), Indian mustard ( $B$. juncea; formerly $B$. japonica), Ethiopian mustard (B. carinata), black mustard (B. nigra), and radish (Raphanus raphanistrum ssp. sativus; formerly $R$. sativus). For many years, TuMV has been considered the most important virus of cultivated brassicid crops in Asia, causing losses in cash crops such as Chinese cabbage, radish and Indian mustard (Green and Deng, 1985; Sako, 1981), among the other crops mentioned above.

Most of the work on genetic resistance to TuMV has been done in brassicid crops; largely in species of the genus Brassica (brassicas), with only a few studies involving radish. These resistance genes are described below. Many have been mapped, but few have been isolated and characterized. In addition, work on genetic resistance has been done in the brassicid species Arabidopsis thaliana, which is not a crop, but whose genome shows synteny with those of brassicas and radish (Kitashiba et al., 2014; Yu et al., 2017a, 2017b). Thus, with its smaller genome and tools available for gene knockout, as well as other genes identified that inhibit TuMV infection, Arabidopsis serves as a potential source of candidates for homologous genes in other brassicids that can be targeted to obtain resistance to TuMV. Finally, the use of non-conventional resistance will also be considered, since it has been applied in resistance to TuMV.

In describing the systems for differentiating TuMV isolates, based on responses in different brassica species, in particular subspecies of $B$. napus and $B$. rapa, as well as characterization of resistance genes from particular host species (see below), generally the English names for these crops will be used here. This is because the specific epithets and subspecies (or variant, or group) names used over the years covered by these activities have changed and the names used in the studies often are not the same names that are used now for those taxa, leading to confusion. Exceptions to this include the analysis of isolates differentiated into their ability to infect local specific cultivars of various brassica species, for which neither English names nor subspecies names were given (see below). There was also a tendency in some publications to use the colloquial term 'brassicas' to refer not just to species in the genus Brassica (as used here), but also to include radish, which is not in the genus Brassica, but is a separate genus (Raphanus) in the family Brassicaceae; describing work involving the inclusion of radish with 'brassica plants' will be referred to here as 'brassicids', meaning members of the family Brassicaceae.

\section{TuMV Genome Structure}

The TuMV genome consists of one single-stranded RNA molecule of $(+)$ polarity and $\sim 9,830 \mathrm{nt}$ (excluding the poly(A) tail); isolates can differ by several nucleotides. The genome organization of TuMV is depicted in Fig. 1. The viral RNA contains a single gene that is translated from an AUG starting $130 \mathrm{nt}$ from the $5^{\prime}$ end of the RNA to produce a single polyprotein of $\sim 300 \mathrm{kDa}$, which ends at nucleotide $9,618,212 \mathrm{nt}$ before the poly(A) sequence at the $3^{\prime}$ end of

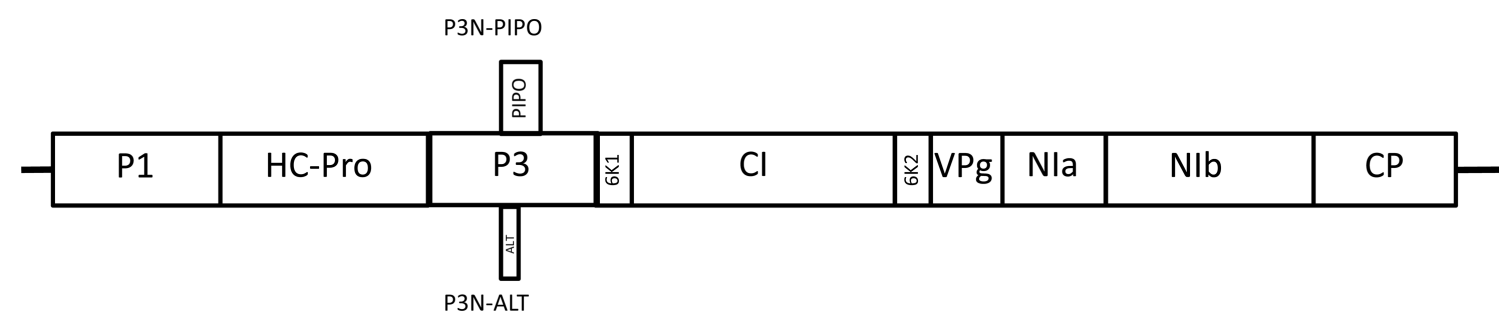

Fig. 1. Schematic diagram of the TuMV genome. The diagram shows the genome (large rectangle) flanked by the $5^{\prime}$ non-translated region (NTR) and 3' NTR (black bars). The singular gene encodes a single polyprotein ( $\mathrm{ca} .300 \mathrm{kDa})$ that is processed into 10 proteins designated P1, HC-Pro (helper component-protease), P3, 6K1 (6 kDa 1 protein), CI (cylindrical inclusion protein), $6 \mathrm{~K} 2$ (6 kDa 2 protein), VPg (viral genome-linked protein), NIa (nuclear inclusion a protease), NIb (nuclear inclusion b RNA polymerase), and CP (coat protein). In addition, two other proteins are generated from the $\mathrm{P} 3$ coding region, by transcriptional slippage at a low level during replication, resulting in translation of the P3 N-terminus (P3N) fused to either the -1 frameshifted protein PIPO to generate P3N-PIPO, or the +1 frameshifted oligopeptide ALT to generate P3N-ALT. 
the RNA (Nicolas and Laliberté, 1992). This polyprotein is processed into 10 mature proteins designated $\mathrm{P} 1$, HC-Pro, P3, 6K1, CI, 6K2, VPg, NIa, NIb, and CP (coat protein). In addition, as the result of a transcriptional slippage (in the -1 frame, about $2 \%$ of the time) within in the P3 encoding sequence, during the synthesis of the viral RNA, translation leads to early termination of the concomitant frame-shifted protein, designated P3N-PIPO (Chung et al., 2008; Olspert et al., 2015; Rodamilans et al., 2015). A further truncated protein, produced by +1 transcriptional slippage in the P3 encoding sequence, designated P3N-ALT, has been identified (Hagiwara-Komoda et al., 2016). The functions of these viral proteins have been reviewed previously (Revers and García, 2015; Walsh and Jenner, 2002) and only their names are shown here (Fig. 1), because resistance breakage to infection by TuMV in some crops has been mapped to some of these proteins, as mentioned below. Since these proteins are all derived from one gene, they will be described individually as 'coding sequences' rather than as individual genes.

\section{TuMV Isolates and Strains: Phylogenetic and Evo-} lutionary Relationships

TuMV isolates have been differentiated and classified into strains based on a number of criteria. Initially, this was by symptoms induced in a range of inoculated plants (Pound, 1948; Pound and Walker, 1945). Later, isolates were differentiated by reactions on specific hosts, such as the two groups of strains observed by Yoshii (1963): one (the 'cabbage strain group') showing severe necrotic ringspots on cabbage plus severe mosaic on Nicotiana glutinosa, and the other (the 'ordinary strain group') producing only mild symptoms on both hosts. Provvidenti (1980) examined various strains using two cultivars and two accessions of Chinese cabbage, and differentiated four groups, designated C1-C4, based on types of symptoms, immunity from infection (i.e., no local or systemic infection), or resistance (i.e., local effects but no systemic infection). A survey of TuMV strains from brassica hosts in Taiwan using various indicator hosts, as well as the same Chinese cabbage indicators, identified the same responses in Chinese cabbage, as well as a fifth response, designated C5 (Green and Deng, 1985). Later, a survey of TuMV isolates from various crops in Ontario, Canada, and their differentiation on Chinese cabbage and rutabaga, identified another Chinese cabbage differential group (Stobbs and Shattuck, 1989), designated $\mathrm{S} 5$ by the authors and $\mathrm{C} 6$ by others. Two additional groups, later designated $\mathrm{C} 7$ and $\mathrm{C} 8$ by others, were identified from a survey of brassica vegetables in China
(Liu et al., 1990), who identified seven groups, Tu1-Tu7. Using a different approach, involving an oilseed rape line immune to infection by the TuMV UK1 isolate, as well as a susceptible oilseed rape line plus a swede line resistant to TuMV UK1, Walsh (1989) was able to distinguish four groups of TuMV isolates, based on their restricted infection or resistance-breaking properties. Subsequently, this was extended to examine 124 isolates of TuMV from around the world, although principally from Europe, for their responses on four differential lines (two oilseed rape and two swede), resulting in 12 distinct pathotype groups (Jenner and Walsh, 1996). These various studies also examined the effects of location of isolation and the classification as to whether such a correlation existed. There was often a tendency for various countries to contain mostly members of one or two pathotypes, but there were many exceptions to such restrictions. The groupings determined by reactions on B. napus (Jenner and Walsh, 1996) vs. B. rapa (Green and Deng, 1985; Provvidenti, 1980) or various brassica differentials (Liu et al., 1990) cannot readily be compared. As pointed out by Jenner and Walsh (1996), B. napus did not differentiate isolates CHN2-CHN5 (all in pathotype 3), which were differentiated on Chinese cabbage (Green and Deng, 1985) into strains C2-C5, respectively, with isolate CHN1 (strain C5) in pathotype 1, while isolates CHN6CHN12 corresponding to strains Tu1-Tu7 (Liu et al., 1990), respectively, were only differentiated in B. napas as isolates CHN6-CHN10 plus CHN12 (all in pathotype 3 ) and CHN11 (in pathotype 1). On the other hand, Walsh et al. (2002) pointed out that strain $\mathrm{C} 1$ and pathotype 1 showed genetically identical interactions with the $B$. rapa and $B$. napus differential lines, indicating that strain $\mathrm{C} 1$ and pathotype 1 are identical.

The first comparison of TuMV CP coding sequences involved 11 isolates and a mutant (UK1M). The phylogenetic analysis showed three distinct groups that generally correlated with geographical and/or the host plant origin of the isolates (Lehmann et al., 1997). With the increase, initially in partial and later in complete, sequence determination of TuMV isolates, other more recent approaches used have involved sequence analysis of the CP coding region (Farzadfar and Pourrahim, 2014; Parmar et al., 2017; Sánchez et al., 2003), the CP and P1 regions (Ohshima et al., 2002), the NIb and CP regions (Korkmaz et al., 2020), or using either most or all of the entire genome (Farzadfar et al., 2009; Gong et al., 2019; Hu et al., 2019; Korkmaz et al., 2008; Tomimura et al., 2003, 2004; Tomitaka and Ohshima, 2006; Wang et al., 2009a; Yasaka et al., 2017), to examine either variation in sequence and infection of particular brassica species or specific changes that affect 
infection of differential hosts.

In a study involving eight laboratories and 76 isolates of TuMV from around the world, Ohshima et al. (2002) assessed the molecular evolution of TuMV by examining the sequence of the $\mathrm{P} 1$ and $\mathrm{CP}$ coding regions, and comparing the phylogenetic data for evidence of genetic recombination and correlation with adaptation to specific hosts and geographical distribution. A phylogenetic grouping by host type and geographical origin had been observed previously by Lehmann et al. (1997) using much fewer isolates. The isolates used by Oshima et al. (2002) came mostly from Brassica and Raphanus crops, but also species in other families. Two pathotypes (referred to further on in this section as 'host types', since this term is used in most later publications, and is equivalent to 'strains') were discerned from the host specificity tests of the various isolates: infecting either brassicas (B) or both brassicas and radish (BR), based on infection in four cultivars of three brassica species and two cultivars of radish. Thus, radish was only susceptible to the BR-host types and not the B-host types; no isolates could infect only radish, while non-brassicid plants were susceptible to both host types. From the sequence analyses, four groups were discerned: (1) a cluster of eight B-host types, which showed the most variation in sequence and were found in both brassica and non-brassica hosts, in Southwest and Central Eurasia, designated the 'basalB' group; (2) a cluster of eight BR-host type isolates from Eurasia, which showed a similar degree of variability and found next to the basal-B group in the phylogeny analyses, designated the 'basal-BR' group; (3) a cluster of 22 BRhost type isolates, all found in brassicids, mostly radish plants, from East Asia, largely from Japan, together showing the least variability in sequence, designated the 'AsianBR' group; and (4) a cluster of 36 isolates, mostly of the B-host type (five isolates from Japan were not B-host types) and mostly obtained from brassicas coming from all continents, designated the 'world-B' group. The 'worldB' group comprised three subgroups: isolates mostly from the 'New World' (Brazil, Canada and New Zealand); isolates from all over the world (Africa, Australasia, Europe, and the USA); and isolates from Russia and the Czech Republic. From this work, the authors concluded that like its brassica hosts, TuMV originated in Europe and spread to all parts of the world, while the BR-host type evolved in East Asia. About $10 \%$ of the isolates showed evidence of recombination between the $\mathrm{P} 1$ and $\mathrm{CP}$ coding regions (Ohshima et al., 2002).

In a different study, Sánchez et al. (2003) determined TuMV strain relatedness among 60 isolates by analysis of the viral $\mathrm{CP}$ coding sequences, using sequencing and typ- ing based on restriction enzymes. This involved 30 isolates characterized experimentally and 30 isolates from the database characterized in silico. They found four groups, comprising two major clusters and two minor clusters. These consisted of (1) mostly Brassica isolates (MB cluster); (2) mostly radish isolates (MR cluster); (3) intermediates between Brassica and radish clusters (IBR); and (4) isolates outside Brassica or radish clusters (OBR). The MB cluster included isolates from Asia, Europe and the 'New World', while the MR cluster contained both European isolates and Asian isolates, although sequences were only obtained from the Asian isolates. The IBR cluster contained isolates from Asia, Europe, and one from Africa, while the OBR cluster contained isolates from Australia, Europe, the 'New World', but not Asia. Sánchez et al. (2003) also suggested that the OBR cluster might represent other genetic lineages not considered by Ohshima et al. (2002), and that the basalB group of Ohshima et al. (2002) might also represent several genetic lineages.

In a subsequent study (Tomimura et al., 2003), the (near) complete sequences of $32 \mathrm{TuMV}$ isolates were determined and compared to six other complete TuMV sequences to further the analysis of relationships, the extent of recombination occurring and to better understand the origin of this virus, the role of recombination in sequence variation and the emergence of new strains. Eight of these isolates showed signs of single [two isolates] or multiple [six isolates] recombination events having occurred in their genomes, between various combinations of world- $\mathrm{B}$, Asian$\mathrm{BR}$ and basal-BR isolates; there were no recombinants found involving basal-B isolates, and all recombinants came from East Asia, predominantly from Japan. The other 30 isolates did not show recombination, but showed variation in sequence such that there was no correlation at any nucleotide or encoded amino acid position with the grouping into B- or BR-host types. [A third host range type was identified as well in this study, designated (B)-host type, which caused a latent infection only in ' $B$. rapa']. The basal-BR and world-BR isolates (probably deriving from Eurasian-B populations), showed the least differences in sequence, while the basal-B isolates (coming mostly from Europe) differed most from each other, up to $18 \%$ in sequence, and might represent the oldest population of TuMV isolates. The world-B isolates were also quite diverse, with three subgroups, as indicated previously (Ohshima et al., 2002), but defined as found in East Europe, the New World, and worldwide (Tomimura et al., 2003). Thus, a lineage from the Eurasia 'B-strain' population, represented now by the basal-B and world-B groups, was considered to be the origin of TuMV. 
A further analysis involving more isolates from both East and West Eurasia (Tomimura et al., 2004), by both sequences analysis (phylogeny and recombination) and host range analysis involving infection of Chinese cabbage, ' $B$. rapa' and radish, confirmed the previously groupings, with West Eurasian isolates in the basal-B, world-B, and basal-BR groups, and East Eurasian isolates in the basal$\mathrm{BR}$, Asian-BR and the Asian lineage of the world-B group. Further subgroups of basal-B were found in Mediterranean countries, and some Asian world-B group members were either BR- or ' $B(R)$ '-host types, where ' $B(R)$ ' represents isolates that infected radish occasionally and latently. From examining the sequences of six coding regions, the West Eurasian isolates were more diverse than the East Eurasian ones, while the diversity estimation between the phylogenetic groups showed that the Asian-BR group was the least diverse and the basal-B was the most diverse. This study also showed that twice as many of the East Eurasian isolates $(80 \%)$ were recombinants, compared with the West Eurasian isolates ( $42 \%$ ), and more of the BR-host type isolates $(74 \%)$ were recombinants than of the B-host type isolates (54\%). Their analysis concluded 'that TuMV in East Eurasia is a more recently emerged population than that in West Eurasia' (Tomimura et al., 2004).

Subsequently, Tomitaka and Ohshima (2006) examined 118 isolates of TuMV from East Asia, utilizing similar methodology, as well as additional methods. They found that 26 isolates from Brassica spp. in China and Taiwan were largely of the B-host type [19], with the rest of either $\mathrm{B}(\mathrm{R})$ - [4] or BR-host type [3], while 12 isolates from radish were all of the BR-host type. By contrast, 17 isolates from brassica in Japan were largely of the BR-host type [14], with only three isolates of the B-host type, while 55 isolates from radish were all of the BR-host type. In the phylogeny analysis, none of the East Asian isolates were in the basal-B group. The Chinese isolates were in both the Asian-BR group and the world-B group, whereas the Japanese isolates were in the Asian-BR, basal-BR, and worldB groups. The recombination analysis showed that $38 \%$ (45 of 118 isolates) of the East Asian isolates were clear recombinants, with 17 recombination patterns, and the [11] Japanese isolates had a greater number of recombination patterns than the [4] Chinese isolates. (Two additional patterns shared by some Chinese and Japanese isolates were considered possible 'false positives'.) The recombination patterns did not show any additional phylogeographical information. Overall, Chinese and Japanese isolates were part of the same population, but formed discrete lineages (Tomitaka and Ohshima, 2006). Later, two basal-BR isolates were identified in China, both being recombinants, either between basal-BR and Asian-BR parents, or between two basal-BR parents (Wang et al., 2009a).

Other studies have examined similar sequence variations associated with local host types and various groupings from isolates in Asia Minor (or most of Turkey) (Korkmaz et al., 2008, 2020), West Asia (Iran) (Farzadfar and Pourrahim, 2014; Farzadfar et al., 2009), South Asia (India) (from radish; Parmar et al., 2017), Vietnam (Nguyen et al., 2013b), Korea (from radish; Gong et al., 2019), and Australia (Nyalugwe et al., 2015b). The Turkish isolates fell into the basal-B, world-B, and Asian-BR groups; the Iranian isolates were in the basal-B and Asian-BR groups; the Indian (radish) isolates were in the basal-BR group; the Vietnamese isolates were in the world-B group; the Korean (radish) isolates were in the basal-BR group; and the Australian isolates were in the basal-B and world-B groups.

From two studies involving the examination of sequences of TuMV isolates from either the entire world (Nguyen et al., 2013a) or world isolates compared to largely isolates from Europe and Western Asia (Yasaka et al., 2017), coupled with Bayesian coalescence analyses, the authors concluded that TuMV arose about 1000 years ago from a European orchid-infecting TuMV-like potyvirus, to become the brassica-infecting TuMV. The orchidinfecting virus could not infect brassica plants initially and represents a sister lineage of the brassica-infecting TuMV isolates. These brassica-infecting isolates diverged into the four lineages of the current global populations of TuMV (basal-B, world-B, basal-BR, and Asian-BR) by 850 years ago in Western Europe. Inter-continental trade by sea, from 500 years ago, facilitated the spread of TuMV to the rest of the world (Nguyen et al., 2013a). Further work indicated that this change in host from orchids to brassicas may have occurred in Germany, and spread subsequently to Asia Minor via Southern Europe about 700 years ago, coinciding with the expansion of the Ottoman Empire and the spread of new agricultural products in the Old World. The basal-B group in Asia Minor is older than other populations, probably originating from the early European brassica-infecting TuMV isolates. The world-B group seems to have originated soon thereafter, as this was found in Greece, Turkey, and Iran. The Asian-BR group may have arisen in either Turkey or Iran and then moved to the other location, as well as into South Asia, all areas that grow radishes. The basal-BR group may have originated in Italy (Yasaka et al., 2017).

The relationship between pathotypes (largely a measure of the extent of infection and types of symptoms) and the phylogenic groupings was examined only in one early study, in which the CP encoding sequences of 60 isolates 
of TuMV were compared (Sánchez et al., 2003), where some of the isolates had previously been among those subjected to pathotyping based on the response in four lines of B. napus (Jenner and Walsh, 1996). No correlation was found between the phylogenic group designation and the pathotype (Sánchez et al., 2003). However, as described above, the phylogenetic groups had different names and biological relationships (MB, IBR, MR, and OBR) and thus are not directly comparable with data obtained in other phylogenic studies (grouped into basal-B, basal-BR, Asian-

Table 1. Comparison of TuMV isolates: pathotype vs. phylogenetic grouping

\begin{tabular}{|c|c|c|c|c|}
\hline Isolate $^{a}$ & Country & Pathotype $^{b}$ & Phylogenetic group & Reference \\
\hline AU1 & Australia & 8 & World-B & Ohshima et al. (2002) \\
\hline BEL1 & Belgium & 7 & OBR & Sánchez et al. (2003) \\
\hline CDN1 & Canada & 4 & World-B & Tomimura et al. (2004), Wang et al. (2009a) \\
\hline CDN2 (aka Q-Ca) & Canada-Quebec & 3 & World-B & Tomimura et al. (2003), Wang et al. (2009a) \\
\hline CHN1 & China & 1 & IBR & Sánchez et al. (2003) \\
\hline $\mathrm{CHN} 2,3,4,5$ & China & 3 & World-B & Ohshima et al. (2002) \\
\hline $\mathrm{CHN} 2,3,4,5,12$ & China & 3 & World-B & Tomimura et al. (2004) \\
\hline CZE1 & Czech Rep. & 3 & World-B & Ohshima et al. (2002), Tomimura et al. (2004) \\
\hline CZE2, 18 & Czech Rep. & 5 & World-B & Tomimura et al. (2004) \\
\hline CZE4, 5 & Czech Rep. & 4 & World-B & Tomimura et al. (2004) \\
\hline DEU1 & Germany & 5 & World-B & Tomimura et al. (2004) \\
\hline DEU2 & Germany & 4 & IBR & Sánchez et al. (2003) \\
\hline DEU4 & Germany & 1 & Basal-BR & Tomimura et al. (2004) \\
\hline DEU5 & Germany & 4 & World-B & Tomimura et al. (2004) \\
\hline FRD1 & Germany & 1 & World-B & Tomimura et al. (2004) \\
\hline PV376 & Germany & 4 & World-B & Ohshima et al. (2002), Tomimura et al. (2004) \\
\hline DNK2, 3 & Denmark & 5 & World-B & Tomimura et al. (2004) \\
\hline DNK4 & Denmark & 3 & World-B & Tomimura et al. (2004) \\
\hline FRA2 & France & 4 & World-B & Tomimura et al. (2004) \\
\hline GBR7 & United Kingdom & 1 & World-B & Ohshima et al. (2002) \\
\hline GBR8 & United Kingdom & 4 & World-B & Tomimura et al. (2004) \\
\hline UK1 & United Kingdom & 1 & World-B & Tomimura et al. (2004) \\
\hline GK1 & Greece & 9 & Basal-B; basal-B2 & Ohshima et al. (2002), Tomimura et al. (2004) \\
\hline GRC2, $6,12,17,18,31,32$ & Greece & 1 & World-B & Tomimura et al. (2004) \\
\hline ITA1 & Italy & 6 & Basal-B & Ohshima et al. (2002) \\
\hline ITA3 & Italy & 10 & Basal-B2; basal-B & Tomimura et al. (2004), Wang et al. (2009a) \\
\hline ITA4 & Italy & 5 & Basal-B2 & Tomimura et al. (2004) \\
\hline ITA5, 6 & Italy & 3 & Basal-B2 & Tomimura et al. (2004) \\
\hline ITA6 & Italy & 3 & OBR & Sánchez et al. (2003) \\
\hline ITA7 & Italy & 1 & Basal-BR & Ohshima et al. (2002), Tomimura et al. (2004) \\
\hline PV377 & Italy & 2 & OBR & Sánchez et al. (2003) \\
\hline JPN1 & Japan & 7 & MR & Sánchez et al. (2003) \\
\hline KEN1 & Kenya & 1 & World-B & Ohshima et al. (2002), Tomimura et al. (2004) \\
\hline NLD1, 2 & The Netherlands & 1 & World-B & Tomimura et al. (2004) \\
\hline POL1, 2, 4 & Poland & 4 & World-B & Tomimura et al. (2004) \\
\hline PRT1 & Portugal & 1 & IBR; world-B & Sánchez et al. (2003), Tomimura et al. (2004) \\
\hline USA1 & USA & 1 & World-B & Ohshima et al. (2002), Tomimura et al. (2004) \\
\hline USA4 & USA & 5 & World-B & Tomimura et al. (2004) \\
\hline UZB1 & Uzbekistan & 7 & Basal-B & Ohshima et al. (2002) \\
\hline
\end{tabular}

TuMV, turnip mosaic virus.

a Isolates described by Jenner and Walsh (1996) used for phylogenetic analysis by citations given in the reference column.

bPathotypes as determined by Jenner and Walsh (1996). 
$\mathrm{BR}$, and world-B) involving much larger numbers of isolates, especially from East Asia. The latter studies, some of which examined the entire genomes, assessed the ability of the isolates to infect selected brassica and radish lines, but not the B. napus lines used by Jenner and Walsh (1996) for their pathotyping. An examination of those isolates pathotyped by Jenner and Walsh (1996), which also were subjected to phylogenic analysis by one or more of three studies (Ohshima et al., 2002; Tomimura et al., 2004; Wang et al., 2009a) using the more common 'basal-B/basal-BR/ Asian-BR/world-B' classification system, is shown in Table 1, along with the results obtained for the same isolates examined by Sánchez et al. (2003). While some isolates with common phylogenic groupings also are in the same pathotypes, especially if they came from the same country (those from the Netherlands and Poland, and for most of those from China or Greece), in other cases, isolates from the same countries can be found in one (or sometimes more) phylogenetic groupings, but in multiple pathotypes. This indicates that there is no general correlation between the pathotype status and the extent of sequence conservation, where the latter allows groupings correlating with infection of brassica and/or radish, in particular in East Asia.

\section{Resistance Genes to TuMV}

Genetic resistance to TuMV has been used in crops since the early 1970's (Zink and Duffus, 1970). However, the first resistance gene mapped for resistance to TuMV was the dominant $T u$ gene in lettuce (Lactuca sativa). The $T u$ gene was shown to be linked to the $D m 5 / 8$ gene for resistance to downy mildew (Bremia lactucae) (Zink and Duffus, 1970), and further mapping by bulk segregant analysis and rapid amplified polymorphic DNA (referred to as RAPD) analysis identified markers close to both the $D m 5 / 8$ and $T u$ loci (Robbins et al., 1994). Subsequent analysis with larger F2 populations identified more markers, including flanking markers 0.8 and 1.5 centiMorgans $(\mathrm{cM})$ from the $T u$ locus (Montesclaros et al., 1997). However, the $T u$ gene was not isolated and characterized.

\section{Resistance Genes in Brassica Crops}

Different Brassica spp. are composed of one or more of three genomes, designated $\mathrm{A}, \mathrm{B}$, and $\mathrm{C}$, comprising the diploids $B$. rapa (AA genome, $2 n=20$ ), $B$. nigra (BB genome, $2 n=16$ ), $B$. oleracea (CC genome, $2 n=18$ ), and the amphidiploids, $B$. juncea (AABB genome, $2 n=36$ ), $B$. napus (AACC genome, $2 n=38$ ), and $B$. carinata (BBCC genome, $2 n=34$ ) (Li et al., 2019a). Most TuMV resistance genes found in brassicas have been found in the A genome of $B$. rapa (Chinese cabbage), but some resistance genes have been found in the $\mathrm{A}$ or $\mathrm{C}$ genomes of $B$. napus, and one has been found in a non-specified genome of $B$. juncea (Table 2). Most TuMV resistance genes characterized have been dominant in nature, although some recessive resistance genes also have been described. For each brassica species below, the dominant resistant genes will be described first (Table 2).

B. napus. Sources of resistance to TuMV were described in field rutabaga (Shattuck and Stobbs, 1987) and in rutabaga/ swede (Doucet et al., 1990). The Tum gene for dominant resistance to TuMV was described for rutabaga in line 165 (Shattuck and Stobbs, 1987), but no further mapping work of this gene appears to have been done.

The first TuMV resistance gene mapped was the $\underline{T u} M V$ Resistance in Brassica 01 (TuRB01) gene (Walsh et al., 1999 ) in oilseed rape. This single dominant gene mapped to a $7.2 \mathrm{cM}$ interval on chromosome N6 of the B. napus A genome and conferred an extreme resistance (no symptoms visible nor virus detected) to pathotype 1 isolates of TuMV. The CI protein (Fig. 1) is the avirulence factor for the TuRBO1 gene and mutants in the CI coding sequence convey resistance-breakage to TuRB01 resistance (Jenner et al., 2000).

The TuRB02 gene, a quantitative trait locus (QTL) for dominant resistance to TuMV, mapped to chromosome $\mathrm{N} 14$ of the $\mathrm{C}$ genome of oilseed rape, and conferred quantitative resistance, in a strain-specific manner to two Asian pathotype 1 isolates of TuMV (Walsh and Jenner, 2002, 2006; Walsh et al., 1999).

The single dominant TuRB03 gene mapped to a $7.9 \mathrm{cM}$ interval on chromosome N6 of the B. napus A genome, in the same interval as TuRBO1, and conferred an extreme resistance to TuMV pathotype 4 isolate CDN1 and some pathotype 3 isolates (Hughes et al., 2003). The avirulence of isolate $\mathrm{CDN} 1$ is associated with the $\mathrm{P} 3$ protein (Fig. 1), with a single amino acid change at position 153 in the Cterminus of the $\mathrm{P} 3$ protein leading to resistance breakage (Jenner et al., 2003).

The TuRBO4 and TuRB05 genes, located in the A genome of swede line 165 (Jenner et al., 2002), together provided extreme resistance to isolates of pathotypes 1 and 3. Neither gene appears to have been mapped further. TURBO4 conditions for an extreme form of resistance to some TuMV isolates, while TuRB05 conditions for a necrotic hypersensitive response limiting systemic movement of some TuMV isolates. TuRB04 is epistatic to TuRB05; i.e., extreme resistance conditioned by TuRBO4 is epistatic 
Table 2. Mapped or isolated genes for resistance to TuMV in crop species of the genus Brassica

\begin{tabular}{|c|c|c|c|c|c|}
\hline $\begin{array}{l}\text { Species } \\
\text { (genome) }\end{array}$ & $\begin{array}{l}\text { Resistance } \\
\text { gene }\end{array}$ & Inheritance & Markers & Pathotypes & Reference \\
\hline B. $\operatorname{napus}(\mathrm{A})$ & TuRB01 & Dominant; $7.2 \mathrm{cM}$ interval on N6 & pN101a pW137cNM & 1 & Walsh et al. (1999) \\
\hline B. napus (C) & TuRBO2 & Dominant; on N14 & pW133a pR113bNM & 1,7 & $\begin{array}{l}\text { Walsh et al. (1999), } \\
\text { Walsh and Jenner } \\
(2002,2006)\end{array}$ \\
\hline \multirow[t]{3}{*}{ B. $\operatorname{napus}(\mathrm{A})$} & $T u R B 03$ & Dominant; $7.9 \mathrm{cM}$ interval on N6 & sS1949a $\sim$ sNRB93 & 4 & Hughes et al. (2003) \\
\hline & TuRB04 & Dominant & $-^{\mathrm{a}}$ & 1,3 & Jenner et al. (2002) \\
\hline & TuRB05 & Dominant & - & 1,3 & Jenner et al. (2002) \\
\hline \multirow[t]{12}{*}{ B. $\operatorname{rapa}(\mathrm{A})$} & $T u 1-T u 4^{b}$ & $\begin{array}{l}4 \text { QTLs: } T u 1 \text { at } 70.4 \mathrm{cM} \text { on } \mathrm{A} 5 \\
\text { Tu2 on } \mathrm{A} 10 \text { (top); } T u 3 \text { at } 58.7 \\
\mathrm{cM} \text { on A3; T4 at } 96.3 \mathrm{cM} \text { on } \\
\text { A4 }\end{array}$ & $\begin{array}{l}T u 1=\mathrm{A} 04-850 \sim \\
\mathrm{CA}+\mathrm{TG} 470 ; \\
T u 2=\mathrm{X} 12-850 ; \\
T u 3=\mathrm{U} 10-1500 \sim \mathrm{CA} \_\mathrm{TC} 157 ; \\
T u 4=\mathrm{CT} \text {-TC710 }\end{array}$ & $\mathrm{C} 4$ & Zhang et al. (2008a) \\
\hline & TuRl-TuR4 & $\begin{array}{l}4 \text { QTLs: } \\
\text { TuR1 at } 2.01 \mathrm{cM} \text { on A3; TuR2 } \\
\text { at } 10.24 \mathrm{cM} \text { on A3; TuR3 at } \\
57.82 \mathrm{cM} \text { on A7; TuR4 at } \\
49.31 \mathrm{cM} \text { on A7 }\end{array}$ & $\begin{array}{l}\text { TuR1=E41M5808 } \\
\sim \mathrm{E} 39 / \mathrm{M} 5305 ; \text { TuR2=E39/ } \\
\quad \text { M505 E42/ M5710; } \\
\text { TuR3=E38/ M5401 E38/ } \\
\text { M5106; } \\
\text { TuR4=E38/M5106 } \\
\text { HpaII650 }\end{array}$ & $\mathrm{C} 3$ & Zhang et al. (2008b) \\
\hline & $T u 1-T u 3^{b}$ & $\begin{array}{l}3 \text { QTLs: Tu1 at } 35.9 \mathrm{cM} \text { on A3; } \\
\text { Tu2 at } 40.8 \mathrm{cM} \text { on A4; Tu3 at } \\
107.3 \text { on A6 }\end{array}$ & $\begin{array}{l}T u 1=\mathrm{E} 36 \mathrm{M} 47-7 \\
T u 2=\mathrm{E} 33 \mathrm{M} 60-5 \\
T u 3=\mathrm{E} 36 \mathrm{M} 59-5\end{array}$ & $\mathrm{C} 4$ & Zhang et al. (2009) \\
\hline & ConTR01 & Dominant; A8. eIF4E ${ }^{c}$ & $\mathrm{pO} 85 \mathrm{e} 1$ & $\begin{array}{l}1,3,4,7 \\
8,9,12\end{array}$ & Rusholme et al. (2007) \\
\hline & TuRBCHO1 & Dominant; at $106.4 \mathrm{cM}$ on $\mathrm{A} 6$ & $\begin{array}{l}\text { E44M48-1 } \\
\text { E36M62-3 }\end{array}$ & $\mathrm{C} 5$ & Xinhau et al. (2011) \\
\hline & $\begin{array}{l}\text { Rnt1-1, } \\
\quad \text { rnt1-2, } \\
\quad \text { rnt1-3 }\end{array}$ & $\begin{array}{l}\text { Dominant; A6; } \\
1-2 \text { incompletely recessive to } 1-3\end{array}$ & $\begin{array}{l}\text { BRMS-221 BRMS-223; } \\
\text { at indel PCR 129-center }\end{array}$ & 1 & Fujiwara et al. (2011) \\
\hline & $T u M V-R$ & Dominant; $3.4 \mathrm{Mb}$ region on $\mathrm{A} 6$ & N0343 CUK_0040i & $\mathrm{C} 4$ & Chung et al. (2014) \\
\hline & $T u R B 07$ & $\begin{array}{l}\text { Dominant; } 1.50-1.62 \mathrm{Mb} \text { on } \mathrm{A} 6 \\
\text { CC-NB-LRR }^{\mathrm{c}}\end{array}$ & $\begin{array}{l}\text { H132A24-s1 } \\
\text { KS10960 }\end{array}$ & $\mathrm{C} 4$ & Jin et al. (2014) \\
\hline & $T u R B 01 b$ & Dominant; $2.9 \mathrm{cM}$ interval on A6 & pN101e1 pW137e1 & $1,7,8,9$ & Lydiate et al. (2014) \\
\hline & TuRBCSO1 & Dominant; $1.9 \mathrm{Mb}$ on A4 & $\begin{array}{l}\text { BrID10723 } \\
\text { SAAS_mBr4055_194 }\end{array}$ & $\mathrm{C} 4$ & Li et al. (2015) \\
\hline & $\begin{array}{l}\text { retr01/ } \\
\text { retr02 }\end{array}$ & $\begin{array}{l}\text { Recessive; A4/0.9 cM interval on } \\
\text { A4. eIF(iso) } 4 \mathrm{E}^{\mathrm{c}}\end{array}$ & $\begin{array}{l}\text { retr } 01=\mathrm{pN} 202 \mathrm{e} 1 \\
\text { retr02 }=\mathrm{BrID} 10694 \sim \\
\mathrm{BrID} 101309\end{array}$ & $\begin{array}{l}1,3,4,7 \\
8,9,12 / \\
\text { C4 }\end{array}$ & $\begin{array}{l}\text { Rusholme et al. (2007), } \\
\text { Qian et al. (2013), } \\
\text { Nellist et al. (2014) }\end{array}$ \\
\hline & $\operatorname{trs}$ & Recessive A4; at/ near retr02 & Scaffold: 000104-040552 & 3 & Kim et al. (2013) \\
\hline $\begin{array}{l}\text { B. juncea } \\
\text { (unknown) }\end{array}$ & TuRBJU01 & Incompletely dominant & - & $1,7,8$ & $\begin{array}{l}\text { Nyalugwe et al. (2015a, } \\
\text { 2016) }\end{array}$ \\
\hline (A) & retr03 & Recessive; A1. eIF2B $\beta^{c}$ & - & 3 & Shopan et al. (2017) \\
\hline
\end{tabular}

TuMV, turnip mosaic virus.

a -, not determined.

${ }^{\mathrm{b}}$ These two studies published by different groups, near in time, used the same names to refer to QTLs located in different positions.

${ }^{\mathrm{c} C}$ Candidate gene. 
to localized necrotic resistance conditioned by $T u R B 05$ (Jenner et al., 2002). The TuRB04-mediated resistance was broken by a mutation at nucleotide 3394 in the P3 coding sequence (encoding a Leu rather than Phe), while the TuRB05-mediated resistance was broken by a mutation at nucleotide 5447 in the $\mathrm{CI}$ coding sequence (encoding a Thr rather than Met) (Jenner et al., 2002). The latter mutation did not affect TuRB01-mediated resistance. It is likely that the TuRB04/TuRBO5 genes are responsible for the resistance mediated by the Tum gene in rutabaga line 165 described by Shattuck and Stobbs (1987).

B. rapa. The turnip cultivar UG1, containing resistance to TuMV, was obtained by crossing a susceptible turnip cultivar with a Chinese cabbage cultivar resistant to TuMV and backcrossing twice to the susceptible turnip cultivar (Shattuck, 1992). No further mapping appears to have been done.

Two studies involving resistance (to TuMV strains C1C5) in the inbred Chinese cabbage line ' $0-2$ ' crossed to different susceptible lines and then backcrossed to the susceptible lines (Suh et al., 1995; Yoon et al., 1993) resulted in very different genetic inheritance conclusions: line ' $0-2$ ' crossed with susceptible lines 'E-7', 'E-9', and 'FL-9' indicated that two recessive genes conferred resistance to infection by either C4 and C5 strains of TuMV (Yoon et al., 1993); however, line '0-2' crossed with susceptible lines 'Seoul', 'SSD31', 'Cheongbang', and 'Yaki 1 ho' gave results indicating resistance to $\mathrm{C} 3$ and $\mathrm{C} 5$ strains of TuMV was conferred by either a single dominant gene (crosses with 'SSD31', 'Cheongbang', and 'Yaki 1 ho') or two dominant genes (crosses with 'Seoul') (Suh et al., 1995). The reason for this difference is not known; however, similar complex results involving the crosses with two other resistant lines and two susceptible lines also yielded such mixtures of contradictory genetic regulation, as described by $\mathrm{Li}$ et al. (2015), referring to their previous study in $\mathrm{Li}$ et al. (2012), in Chinese. It may be that crosses to some genotypes introduced either epistatic genes controlling the resistance, or other resistance regulators.

Three sources of resistance to TuMV were characterized in different lines of Chinese cabbage: the cultivar 'Tropical Delight', and lines BP058 and BP079 (from Liu et al., 1996). 'Tropical Delight' showed immunity to infection by TuMV strains of pathotypes 1 and 7, and local necrotic lesions but systemic resistance to strains of pathotypes 8 and 9, while lines BP058 and BP079 showed either immunity or systemic resistance to all strains tested, representing pathotypes $1,3,4,7,8,9$, and 12 , with line BP058 generally showing a stronger resistance effect on virus local move- ment than line BP079 (Walsh et al., 2002). The resistance in the cultivar 'Tropical Delight' was characterized further (see below).

Three other studies disclosed QTLs associated with resistance to TuMV in Chinese cabbage. The first of these studies mapped four QTLs in double-haploid lines: two QTLs (Tu1 and Tu2) for dominant resistance at the seedling stage against a TuMV C4 strain, with Tu1 mapping at $70.4 \mathrm{cM}$ on linkage group 5, between markers A04-850 and CA TG270, explaining $58.2 \%$ of the phenotypic variation, and Tu 2 mapping at the top of linkage group 10, with marker X12-850, explaining $14.7 \%$ of the phenotypic variation; and two QTLs (Tu3 and Tu4) for dominant resistance at the adult stage for field resistance, with Tu3 mapping at 58.7 $\mathrm{cM}$ on linkage group 3, between markers U10-1500 and CA_TC127, explaining $48.5 \%$ of the phenotypic variation, and Tu4 mapping $96.3 \mathrm{cM}$ on linkage group 4, with marker CT_TC710, explaining 32\% of the phenotypic variation (Zhang et al., 2008a). In the second study, a different group (Zhang et al., 2008b) mapped four QTLs for resistance to a TuMV C3 strain: TuR1 and TuR2, both on linkage group 3 , mapping at $2.01 \mathrm{cM}$ between markers E41/M5808 and E39/M5305, and at $10.24 \mathrm{cM}$ between markers E39/M505 and E42/M5710, respectively, accounting for $29.05 \%$ and $16.75 \%$, respectively, of the phenotypic variance; and with $T u R 3$ and TuR4, both on linkage group 7, mapping at 37.82 cM between E38/M5401 and E38/M5106, and at $49.31 \mathrm{cM}$ between E38/M5106 and HpaII650, respectively, accounting for $8.35 \%$ and $6.25 \%$, respectively, of the phenotypic variation. In the third study, another group (Zhang et al., 2009) also using double-haploid lines, located three QTLs for resistance to a TuMV C4 strain: Tu1 mapped on linkage groups 3, at $35.9 \mathrm{cM}$ and at marker E36M47-7, accounting for $10.5 \%$ of the phenotypic variance; Tu2 mapped on linkage group 4, at $40.8 \mathrm{cM}$ and at marker E33M60-5, accounting for $21.9 \%$ of the phenotypic variation; and Tu3 mapped on linkage group 6 at $107.3 \mathrm{cM}$ and at marker E36M59-5, accounting for $14.5 \%$ of the phenotypic variation.

An epistatic relationship was delineated between two resistance genes in Chinese cabbage line RLR22, leading to broad-spectrum resistance against TuMV pathotypes 1 , 3, 4, 7, 8, 9, and 12 (Rusholme et al., 2007). The resistance was conferred by both ConTR01 (Conditional $\underline{T} u M V \underline{R} e-$ sistance 01 ), a dominant single gene located on the upper arm of chromosome R8 (aka A8) of B. rapa ssp. pekinensis, and retr01 (recessive $\underline{T} u M V$ resistance $\underline{01}$ ), a recessive single gene located on the upper portion of chromosome R4 (aka A4), with retr01 epistatic to ConTR01. ConTR01 mapped to a region coincident with three loci encoding eukaryotic translation factor 4E (eIF4E) and possibly one lo- 
cus encoding eIF(iso)4E, while retr01 mapped to a region coincident with one of three loci encoding $\mathrm{EIF}$ (iso)4E in the A genome of B. napus, and thus probably also in B. rapa. More recently, the specific genes corresponding to the loci of ConTR01 and retr01 have been identified and their relationships discerned (Nellist et al., 2014). [Note: eIF4E plus eIF4G form a complex called eIF4F, required for formation of the translation initiation complex (Marcotrigiano et al., 1999). In plants, there is a second translation initiation complex, eIF(iso)4F, containing eIF(iso)4E and eIF(iso)4G (Browning, 2004).]

A cDNA corresponding to a gene designated $B c T u R 3$ was cloned from a non-headed Chinese cabbage variety (line Duanbaigeng), which contains a dominant resistance to TuMV, exhibiting a hypersensitive response upon infection. The expression of this gene was elevated in both a resistant and a susceptible cultivar, with differences in the kinetics of expression between these two cultivars after inoculation with TuMV, with greater expression in leaves than in stems or roots (Ma et al., 2010). The sequence of the $B c T u R 3$ gene indicated that it encoded an 829-amino acid $(97.3 \mathrm{kDa})$ protein, containing TIR (Toll/interleukin receptor), NB (nucleotide binding), and LRR (leucine-rich repeats) domains, typical of some dominant resistant genes activating a hypersensitive response. However, the $B c T u R 3$ gene was not confirmed as the resistance gene, nor was the sequence of its susceptible allele analyzed. Therefore, at present this remains only a candidate resistance gene.

A single dominant resistance gene to a TuMV C5 strain in pak choy (B. rapa ssp. chinensis) was mapped on linkage group 6 at $106.4 \mathrm{cM}$, in a region between the amplified fragment length polymorphism markers E44M48-1 (84.4 $\mathrm{cM})$ and E36M62-3 (114.3 cM). The resistance gene was designated TuRBCHO1 (Xinhau et al., 2011). The derivation of the gene name was given in an earlier publication

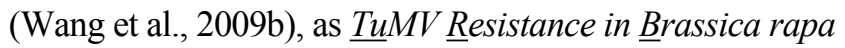
ssp. chinensis 01 .

A complex of three allelic or closely linked genes was identified using three cultivars and various crosses of Chinese cabbage that controlled different responses to either the TuMV UK1 strain (pathotype 1) or a mutant of TuMV UK1 (UK1-CIm), with a single alteration in the CI region encoding amino acid 1827, from Val to Glu (Fujiwara et al., 2011). The genes were designated Rnt1-1 (for Resistance and necrosis to $\underline{T} u M V$ ), rnt1-2 and rnt1-3, with the first gene being dominant and the latter two genes being recessive, while rnt 1-2 was incompletely recessive to $r n t 1$ 3. Rnt1-1 induced resistance to TuMV UK1, while rnt12 induced systemic necrosis and rnt1-3 induced mosaic symptoms, with the heterozygous combination rnt1-2/rnt1-
3 causing leaf malformation, as well as some necrosis on leaf veins, the exact symptoms fluctuating with genetic backgrounds and environmental conditions. TuMV UK1CIm infection broke resistance mediated by Rnt1-1, leading to systemic necrosis, while inhibiting systemic necrosis mediated by rnt1-2. Rnt1-1 mapped to linkage group R6, between simple sequence repeat (SSR) markers BRMS221 and BRMS-013, co-segregating with indel PCR marker 129-center (Fujiwara et al., 2011).

A genetic map, based on high-throughput single nucleotide polymorphism (SNP) genotyping and mapping of a resistance locus against a TuMV C4-strain, in a double-haploid population of a leafy Chinese cabbage cultivar (VC40), identified the location of the resistance gene (designated $T u M V-R$ ) at a $3.4 \mathrm{Mb}$ region in the short arm of linkage group A6, between markers N0343 and CUK_0040i (Chung et al., 2014). This region contains 56 genes, including four genes encoding CC-NB-LRR proteins and two genes encoding PR-1 proteins. [Note. Some dominant resistance genes conferring a hypersensitive response encode proteins containing a coiled-coil (CC) domain near the Nterminus, rather than the TIR domain.] A comparison of the sequences of these six genes, between the resistant cv. VC40 and the susceptible cvs. SR5 and Chiifu, showed non-synonymous sequence substitutions in each gene. The sequences and positions of flanking markers of this $T u M V$ $R$ gene did not coincide with those of any previously reported TuMV resistance genes (Chung et al., 2014).

A single dominant gene for resistance to a TuMV C4 strain (designated TuRB07) was mapped in crosses between the resistant Chinese cabbage line VC1 and the susceptible line SR5, using SSR marker analysis, to a region on the upper arm of linkage group A6, between markers H132A24s1 and KS10960. These markers were located physically at $1.50 \mathrm{Mb}$ and $1.62 \mathrm{Mb}$ on chromosome A6 (Jin et al., 2014). This region contains 28 predicted genes, of which 22 were annotated and six were unknown genes. Two of these genes, designated Bra018863 and Bra018862, encode CC-NB-LRR proteins, with the later gene truncated. These genes are at or above the marker KS10960, while marker N0343, which is below KS10960, is above the four genes encoding CC-NB-LRR proteins that coincided with the $T u M V-R$ resistance gene (Chung et al., 2014). In addition, both genes Bra018863 and Bra018862 showed differences in sequence from each other between the susceptible SR5 line and the resistant $\mathrm{VC} 1$ line, as well as from the susceptible reference genome, line Chiifu. Given the truncated nature of Bra018862, the authors suggest that Bra18863 may be the TuRB07 gene (Jin et al., 2014).

The dominant resistance to pathotype 1 strains of TuMV, 
identified in cultivar 'Tropical Delight', was mapped to a region on linkage group A6, in an interval of $2.9 \mathrm{cM}$, flanked by restriction fragment length polymorphism markers pN101e1 and pW137e1, coincident with the position of the TuRBO1 resistance gene on chromosome N6 of the A genome of B. napus, and thus was named TuRB01b (Lydiate et al., 2014). TuRB01 was thought to be the same gene from the A genome of $B$. rapa (genome AA), with $B$. napus (genome AACC) acquiring this gene from the $\mathrm{A}$ genome gene pool of B. rapa. TuRB01b was at a different chromosomal location from both the TuMV-R locus identified by Chung et al. (2014) and the TuRB07 locus identified by Jin et al. (2014), both also on linkage group A6.

A single dominant gene for resistance to a TuMV C4 strain (designated TuRBCSO1) was mapped in crosses between the resistant Chinese cabbage line 8407 and the susceptible line Guan291, using expressed sequence tags, SSR, and indel marker analysis, to a $1.98 \mathrm{Mb}$ region on linkage group A4, between markers BrID10723 and SAAS_mBr4055_194 (Li et al., 2015). The derivation of the name TuRBCSO1 was not described.

A study examining the expression patterns of genes encoding TIR-NB-LRR proteins in Chinese cabbage identified 16 candidate genes that were expressed in leaves early in infection, making them possible candidates for resistance, although not associated with any known resistance genes (Lv et al., 2015).

A single recessive gene, retr02, in Chinese cabbage line BP8407, resistant to a TuMV C4 strain, was identified and mapped after crosses to the susceptible line ' $\mathrm{Ji}$ Zao Chun', to a $0.9 \mathrm{cM}$ interval between the two Indel markers BrID10694 and BrID101309 on chromosome A4. A candidate gene, Bra035393, on scaffold000104, was predicted to be within this locus (Qian et al., 2013). This gene encodes an $\operatorname{eIF}$ (iso)4E protein. A single (A/G) polymorphism was found in exon 3 of this gene in between BP8407 and ' $\mathrm{Ji}$ Zao Chun', leading to a difference in the codon for Gly vs. Asp in the resistant vs. susceptible line. The same observation was made by sequencing this gene from two other susceptible lines and three other resistant lines (Qian et al., 2013). If line BP 8407 used here is the same as line 8407 used by $\mathrm{Li}$ et al. (2015) for isolation of the dominant resistant gene TuRBCS01 (from line $8407 \times$ line Guan291), then the retr02 recessive resistance gene may be the recessive gene Li et al. (2012) described occurring from the cross of line $8407 \times$ line $06-247$. The situation may be more complicated since in the hybrid of the resistant line $73 \times$ susceptible line 06-247 resistance also was controlled by a single recessive gene, but in the hybrid of line $73 \times$ line Guan291 resistance was controlled by two recessive genes ( $\mathrm{Li}$ et al., 2012). Since retr02 has been shown to be the same as retr01, rather than an allele (Nellist et al., 2014) and both produce a mis-spliced mRNA leading to a truncated eIF(iso)4E, the understanding of the mechanism of action of this gene has changed (Nellist et al., 2014). Li et al. (2016a) developed two markers for retr02, to assist in breeding: a dCAPS-BslI marker, and a KASP_retr02 marker.

A broad-spectrum recessive resistance gene was identified in Chinese cabbage lines SB18 and SB22, which was shown to be the same gene. This gene was designated trs (for TuMV resistance discovered at Seoul National University) (Kim et al., 2013). Since various recessive genes for resistance from B. rapa (Rusholme et al., 2007; Qian et al., 2013) and A. thaliana (Duprat et al. 2002; Lellis et al., 2002; Sato et al., 2005) were either shown or indicated to encode eIF(iso)4E, Kim et al. (2013) used a candidate gene approach to determine whether the gene trs mapped with one of the genes encoding $\operatorname{eIF(iso)4E.~The~mapping~}$ involved the development and use of SNPs and sequencecharacterized amplified region markers, as well as cloning the three $B$. rapa eIF(iso)4E genes, with two alleles of one gene, designated Braiso4Ea-1, Braiso4Ea-2, Braiso4Eb, and Braiso4Ec. However, further analysis indicated that none of these genes was the trs gene, which also mapped to chromosome A4, between scaffold000104 and scaffold040552 (Kim et al., 2013), at or near the retr02 locus (Qian et al., 2013). Thus, trs may be either another allele of retr01/retr02, or closely linked to that gene.

The Chinese cabbage cultivar 'Norang' was shown to be resistant to 17 Korean radish isolates of TuMV (Gong et al., 2019), but could be infected by a recombinant virus composed of parts of two isolates (KIH1 and KJY1) that differed in their phenotypes on $N$. benthamiana (Kim et al., 2019). The nature of the resistance in cv. 'Norang' has not been identified.

Possible candidate genes for screening for either resistance or polymorphism identifying resistance to TuMV were identified in Chinese cabbage cv. 'Chiifu-401-42' (Zhang et al., 2018). These authors examined the expression analysis of SNARE (soluble- $\underline{N}$-ethylmaleimide-sensitive-factor accessory-protein receptor) genes as a function of TuMV infection, and identified nine genes potentially associated with virus cell-to-cell movement and 15 genes associated with long-distance movement. SNARE proteins play roles in various aspects of intracellular and intercellular trafficking and vesicle-mediated transport, and one SNARE protein, Syp71, was shown to be essential for TuMV infection in Arabidopsis (Wei et al., 2013). Therefore, other SNARE proteins may also have roles in promot- 
ing virus infection.

B. juncea. Of four cultivars of $B$. juncea ssp. crispifolia, only one ('Southern Giant Curled') showed good (72\% and $81 \%$ ) resistance to $\mathrm{C} 1$ and $\mathrm{C} 2$ strains of TuMV, respectively, while a second cultivar ('Red Leaved Mustard') showed good resistance (90\%) only to a C2 strain, with no resistance among the four cultivars against $\mathrm{C} 3$ or $\mathrm{C} 4$ strains (Fjellstrom and Williams, 1997).

Of 44 accessions, lines, or cultivars of Indian mustard tested for resistance to TuMV using one isolate of pathotype 8 (Kehoe et al., 2010), none showed extreme resistance, one showed only susceptibility without necrosis, 16 showed a single phenotype (with eight showing systemic infection with necrosis, seven showing local necrosis and systemic infection either alone [six] or plus necrotic stem streaking [one], and one showing severe systemic necrosis), 25 showed two different phenotypes, and three showed three different phenotypes. Only two showed resistance with only local necrosis and including necrotic stem streaking. These two resistant phenotypes occurred only in one plant each of 10 and 17 plants, respectively. In addition, 13 variants were re-tested with this same pathotype 8 isolate, as well as tested with one isolate each of pathotypes 1 and 7, with similar but not identical results. The authors consider both local necrosis and systemic necrosis as measures of resistance (Kehoe et al., 2010). A subsequent survey of 69 Indian mustard lines identified various forms of resistance with local necrosis or systemic necrosis occurring in most of them (47 of 69 lines), often segregating for different necrotic phenotypes, and with only one line showing complete susceptibility with no necrosis and 21 lines segregating for either susceptibility or different necrotic phenotypes. However, there were no cases of extreme resistance, or resistance to systemic movement with and without local necrosis (Nyalugwe et al., 2015a). This study also further analyzed one line showing a systemic cell death response ('Oasis $\mathrm{C1}$ ') and showed that it was conditioned by the presence of a single, incompletely dominant gene designated TuRBJU01, derived from $\underline{T u} M V \underline{\text { Resistance in } \underline{B} \text { rassica }}$ juncea $\underline{01}$ (Nyalugwe et al., 2015a). Further analysis was done using line 'Oasis $\mathrm{Cl}$ ', its susceptible cross partner (JM 06006), and their $F_{3}$ progeny by infection with 10 isolates of TuMV, two each belonging to pathotypes $1,7,8$, a new pathotype (isolates NSW-3 and NSW-4), or not pathotyped (but resistance-breaking on B. napus) (Nyalugwe et al., 2016). This analysis showed that TuRBJU01 conditioned for the systemic necrosis phenotype with all isolates except for one of the two above new pathotype isolates (NSW-3), which caused systemic mosaic symptoms. In addition, the
TuRBJU01-mediated resistance was less effective against the two above not-pathotyped isolates (12.5 and 12.1), as determined by altered segregation ratios of necrotic vs. mosaic symptoms. The gene appears not to have been mapped further.

In a study by a different group (Shopan et al., 2017), a collection of 35 accessions of Indian mustard were screened for resistance to TuMV isolates CHN3 and CHN4 (pathotype 3). Ten of these accessions were resistant to infection by these TuMV isolates, and one accession was used for further genetic analysis by crossing with susceptible line STZ. A single recessive gene in Indian mustard resistant line VC029 was obtained and was designated retr03. Bulk segregant analysis of the parents (recessive resistant line VC029 and dominant susceptible line STZ) and $\mathrm{F} 2$ progeny was done by resequencing the genomes. Further in situ analysis delimited the resistance gene to BjuA006209 on chromosome 1 of the A genome of B. juncea (AABB genomes). This gene encodes the eukaryotic translation initiation factor 2B-Beta (eIF2B 3$)$. [eIF2B is a dimer of five distinct subunits $(\alpha-\varepsilon)$, which functions during early translation initiation by binding to an eIF5-eIF2-GDP complex to facilitate release of eIF5 and formation of eIF2GTP for cycling back into assembling the early translation initiation complex (Jennings and Pavitt, 2014).] A second ortholog of this gene in the A sub-genome and one in the $\mathrm{B}$ sub-genome were eliminated from further consideration by genotyping using SNPs, with only one SNP of 30 present in this gene from the two parental genomes being non-synonymous (A129G). Genotyping also revealed that all seven susceptible lines examined encoded the amino acid Ala at this non-synonymous SNP, while four of the seven resistant lines examined encoded Gly and three lines encoded Trp. Furthermore, silencing BjuA006209 in the susceptible line STZ, using turnip yellow mosaic virus as a vector for virus-induced gene silencing, retained susceptibility to TuMV infection in those plants with normal expression of the BjuA006209 gene (i.e., insufficient gene silencing) but resistance to TuMV infection in plants with reduced expression of the BjuA006209 gene. Similarly, expressing the $e I F 2 B \beta$ gene encoded by BjuA006209 from the susceptible line STZ, using the turnip yellow mosaic virus vector, within the resistant line VC029 (presumably containing a non-functional $e I F 2 B \beta$ gene, with respect to a functional interaction required for TuMV infection), and subsequent infection by TuMV, resulted in TuMV infection of the resistant line. A 90-bp insertion was detected in the third intron of the susceptible (STZ) line, which was absent from the resistant (VC0290) line. This allowed the development of a molecular marker $(B j T u R)$ specific for the retr03 re- 
sistance gene in all of the lines examined (Shopan et al., 2017).

B. carinata. Analyzing one cultivar and eight accessions of Ethiopian mustard (genome BBCC) for resistance to infection by a TuMV pathotype 1 isolate, Kehoe et al. (2010) found the following patterns: (1) only resistance to systemic infection (one accession); (2) segregation for systemic resistance with or without local necrosis (three accessions); (3) segregation for systemic resistance or extreme resistance (one accession); and (4) segregation for systemic resistance, either with or without local necrosis, or extreme resistance (three accessions and one cultivar). Testing two of these accessions with TuMV isolates in pathotypes 1 or 7 showed similar but not identical segregation of extreme resistance and systemic resistance with or without local necrosis (Kehoe et al., 2010). A follow-up study involving 32 variants (accessions, breeding lines and cultivars) of Ethiopian mustard inoculated with a pathotype 1 TuMV isolate showed similar results (Nyalugwe et al., 2014). In this study, only one accession from Pakistan showed complete susceptibility, while the other variants showed (1) extreme resistance (14 variants); (2) systemic resistance either with (two variants) or without (two variants) local necrosis; (3) segregation for systemic resistance either with or without local necrosis (one accession); (4) or segregation for extreme resistance and systemic resistance (12 variants) (Nyalugwe et al., 2014). It is not known if the resistances described originated from the $\mathrm{B}$ or $\mathrm{C}$ genomes of $\mathrm{B}$. carinata. No further mapping appears to have been done.

In analyzing the resistance phenotype to TuMV in Ethiopian mustard, with infection by a pathotype 1 strain (UK1) of TuMV and apparent non-infection by a pathotype 7 isolate (JPN1), the resistance was associated with restricted systemic movement and absence of symptoms. The restricted vs. resistance-breaking phenotype mapped to the C-terminal region of the $\mathrm{P} 3$ protein, with a major determinant being amino acids 1099 and 1100 of the polyprotein, equivalent to amino acids 279 and 280 of the P3 protein (Sardaru et al., 2018). These changes in phenotype may be due, in part, to the same amino acid pairs (Lys-Met vs. Thr-Ile) at positions 279 and 280, respectively, appearing to be involved in the ability to infect radish (Suehiro et al., 2004), with Thr-Ile leading to restricted infection of Ethiopian mustard, and Lys-Met leading to the inability to infect radish.

B. nigra. An analysis of five accessions of black mustard (genome BB) for resistance to a pathotype 8 isolate of TuMV, showed that all plants became systemically infected, but displaying two (two accessions), three (two accessions), or four (one accession) combinations of four different phenotypes: (1) susceptible; (2) susceptible with local necrotic spots plus necrotic stem streaking; (3) local necrosis and systemic infection; and (4) severe systemic necrosis. All accessions showed some plants completely susceptible to infection. Similar phenotypes were produced, involving systemic infection with mild or severe systemic necrosis, when the experiments were done with TuMV isolates of pathotype 1 or 7 (Kehoe et al., 2010). No extreme resistance was observed.

B. oleracea. These were all screening studies and no further mapping work appears to have been done on any of these resistance responses.

Walkey and Neely (1980) screened 88 white cabbage cultivars and breeding lines for resistance to TuMV. In the greenhouse, all 88 accessions were infected, but some of 49 accessions tested showed resistance in the field, identified by reduced symptom expression. Subsequently, Walkey and Pink (1988) examined the infection of four cultivars of white cabbage with four strains of TuMV. They found that three of the cultivars were highly resistant to the UK strain of TuMV (probably the one later referred to as UK2), while the levels of resistance in these three cultivars varied against the other three strains, varying in the degree of internal necrosis, external necrosis and yield depression. Sevik and Deligoz (2016) screened 23 cabbage breeding lines and identified nine lines as 'highly resistant' (with five lines showing no symptoms or detectable virus), one as 'resistant', and seven as 'moderately resistant' to infection by a local cabbage strain of TuMV.

Tomlinson and Ward (1981) concluded that resistance in Brussels sprouts to TuMV was due to a partially dominant gene; however, Pink et al. (1986), using a larger number of accessions for their analysis, concluded that resistance in Brussels sprouts was due to contributions from at least four genes.

Cabbage (three cultivars), cauliflower (two cvs.), kale (one cv.), kohlrabi (one cv.), Brussels sprouts (one cv.), and broccoli (one of two cvs.) inoculated with isolates of TuMV pathotypes 1,7 , and 8 , all showed extreme resistance, while the second broccoli cv. showed segregating systemic resistance and extreme resistance (Nyalugwe et al., 2015a).

Guerret et al. (2017) examined responses to five isolates of TuMV (one each in pathotypes 1, 7, and 8, and two unpathotyped isolates) against one cultivar of each of three subspecies of $B$. oleracea, with the following results: (1) cauliflower was extremely resistant to all of the isolates; 
(2) cabbage showed extreme resistance to pathotype 8, segregating extreme resistance and systemic resistance with symptomless local infection to pathotypes 1 and 7, and segregating extreme resistance and systemic infection with the two unpathotyped isolates: and (3) broccoli showed extreme resistance to pathotypes 1 and 7, local symptoms and systemic resistance to pathotype 8 , and susceptibility to the unpathotyped isolates (Guerret et al., 2017).

\section{Resistance Genes in Radish}

The first identification of resistance to TuMV in radish was actually done in an artificially synthesized Raphanobrassica hybrid $(2 n=36$, with RRCC genomes), generated from radish ( $2 n=18$, RR genome; susceptible to TuMV) and kale (B. oleracea var. acephala; $2 n=18, \mathrm{CC}$ genome; resistant to TuMV). This hybrid line was backcrossed to susceptible radish to obtain seven monosomic addition lines of radish, each with one kale chromosome (a-g; $2 n=$ $19)$, as well as revertant radish plants $(2 n=18)$. These various lines, as well as the progeny of further backcrosses of the seven monosomic lines to radish, were each tested for resistance to TuMV. The data showed that only plants of the monosomic line with the f-chromosome from kale (ftype line), were resistant to TuMV (Kaneko et al., 1996). It does not appear as if further work was published on the mapping of this trait.

A survey of brassicid species identified resistance to TuMV of pathotype 8 in three radish cultivars, with extreme resistance in two cultivars ('Long Scarlet' and 'Sparkler') and extreme resistance segregating with systemic resistance plus local necrosis in the third cultivar ('Daikon Mooli Minowase') (Nyalugwe et al., 2015a). Extreme resistance in cultivar 'Daikon' was also observed against a pathotype 1 isolate (UK1) and a pathotype 8 isolate (JN1) of TuMV (López-González et al., 2017). In a subsequent study, five isolates of TuMV (one each in pathotypes 1, 7 and 8 , and two unpathotyped isolates) were tested against the cultivar 'Sparkler', showing extreme resistance to all tested isolates (Guerret et al., 2017). No genetics or mapping work appears to have been done on these resistance responses.

Four of 17 TuMV isolates obtained from a survey of infected radish plants in Korea were not able to infect the radish cv. 'Iljin', while all 17 isolates could infect the cv. 'Chunghwa' (Gong et al., 2019). The nature of neither the avirulence factor nor the resistance has been identified.

A determinant for infection of radish by TuMV strains was found in the $\mathrm{C}$-terminal region of the $\mathrm{P} 3$ protein, with the identities of P3 C-terminal-region amino acids 268, 279 and 280 correlating with the ability to infect radish (Suehiro et al., 2004).

Other examples of genetic resistance to TuMV appear to be limited to reports published as thesis dissertations, as reviewed by $\mathrm{Yu}$ et al. (2017b). Using an F2 segregating population of two inbred radish lines (Q07-12P1 × KB0710P2), which differed in resistance to TuMV, Li (2009) identified two QTLs related to TuMV resistance, one with a positive effect on the resistance and one with a negative effect. Bulk segregant analysis was used to tag the TuMV resistance gene to a marker with a genetic linkage distance of $7.9 \mathrm{cM}$. Cheng (2013) cloned two radish genes encoding the translation initiation factors eIF4E and eIF(iso) $4 \mathrm{E}$ and suggested they may be involved in resistance. Cheng et al. (2013) described a method for locating markers by a target region amplification polymorphism (referred to as TRAP) using expressed sequence tags and information concerning resistance gene analogs. They used this method to establish a correlative relationship between marker genotypes and TuMV resistance phenotypes among 30 radish genotypes, producing a cultivar identification diagram.

\section{Resistance Genes in Arabidopsis}

The first analysis of resistance to TuMV in Aradidopsis was a screen of 106 ecotypes for responses to infection by the TuMV strain UK1, in which four ecotypes (Bay-0, Di0 , Er-0, and Or-0) were found to be resistant to systemic infection of TuMV, while Bay-0 also showed resistance to cell-to-cell movement of the virus (Martin Martin et al., 1999).

The first single dominant resistance gene to TuMV described for Arabidopsis, was a gene responsible for systemic veinal necrosis in the $A$. thaliana ecotype Landsberg erecta (Ler) (Kaneko et al., 2004). The TuMV necrosis inducer ( $T u N I$ ) gene was shown to be located on chromosome 1 in a $\sim 105 \mathrm{~kb}$ interval between two markers (mXF41 and mRF28), containing 19 putative genes, of which 15 were classified into five gene families. Subsequent chromosomal walking, cloning and sequencing analysis identified a trio of direct repeat variant genes, designated $R G X$, $R G 2$ and $R G 3$ as being involved in resistance to TuMV (Liu et al., 2015). The three genes were isolated and characterized. They each encoded proteins containing CC-NBSLRR domains and shared nearly identical sequences from the transcription initiation site (TIS) to the NBS domain, while $R G 2$ and $R G 3$ shared $99 \%$ sequence identity for 9 $\mathrm{kb}$ upstream from the TIS. All three genes shared similar 
promoter sequences to $200 \mathrm{bp}$ upstream of the TIS. The $R G 2$ gene encoded a truncated protein terminating just before the LRR domain, but might still have an active function. The $R G 3$ gene encoded a rearranged chimeric LRR domain, longer than the one encoded by the $R G X$ gene (Liu et al., 2015). Further work involving either transient expression or transgenic expression of each of three genes indicated that the $R G X$ gene was the primary determinant of the resistance and suggested that the $R G 2$ and $R G 3$ genes played additional roles in regulating the induced necrosis, since $R G X$ alone did not produce systemic veinal necrosis, but only induced necrotic spots and chlorosis after TuMV infection, while $R G 2$ and $R G 3$ themselves induced no necrotic symptoms. Transient expression of $R G 2$ or $R G 3$ together with either TuMV or the TuMV P3 encoding sequence in Arabidopsis protoplasts did not reduce cell viability, while a similar assay involving $R G X$ greatly reduced cell viability (Liu et al., 2015); previous work by this group had identified the P3 as the avirulence factor for the TuNI gene (Kim et al., 2010) and had shown that the TuNI gene induced defense responses associated with a hypersensitive response-like cell death (Kim et al., 2008). Additional work involving promoter analysis showed that the $R G X$ gene was induced by TuMV and suppressed by dark treatment (Liu et al., 2015), as was the case for the TuNI gene response (Kim et al., 2008). Thus, this complex of three genes involved in the TuNI response was the first dominant NB-LRR $R$-gene cluster isolated for resistance to TuMV.

The first Arabidopsis gene identified, isolated and characterized for recessive resistance to any plant virus was the loss-of-susceptibility to potyviruses 1 (lspl) gene, which showed resistance to infection by both TuMV and tobacco etch virus (Lellis et al., 2002). The lspl locus was mapped to chromosome 5, to an interval of $\sim 200 \mathrm{~kb}$ between markers MOK9-39s and MXH1-36116 Taq. The lsp1 gene encoded eIF(iso)4E, which had previously been shown to interact with the TuMV VPg protein (Wittmann et al., 1997). A similar conclusion was reached from an analysis of Arabidopsis plants from a transposon insertion library in which an eIF(iso)4E mutant line was identified and shown to be resistant to TuMV and the potyvirus lettuce mosaic virus (Duprat et al., 2002). These studies led to testing genes encoding eIF4E, eIF(iso)4E, as well as other eukaryotic translation factors, of other plant species, as candidate recessive resistance genes (reviewed by Shopan et al., 2020a, 2020b). Another study also showed that an Arabidopsis mutant line with a mutation in eIF(iso)4E was unable to support infection by TuMV, but supported infection by the potyvirus clover yellow vein virus, while an
Arabidopsis mutant line with a mutation in eIF4E was able to support infection by TuMV, but not clover yellow vein virus (Sato et al., 2005). Interestingly, TuMV could infect an Arabidopsis eIF4E knockout mutant line transformed with either eIF4E or eIF(iso)4E from a diploid B. rapa ssp. trilocularis (yellow sarson; aka field mustard), although the mutant lines expressing the $B$. rapa eIF4E genes were less efficient (Jenner et al., 2010). Other work showed that either Arabidopsis eIF(iso)4G1 or eIF(iso)4G2 could be used by TuMV, but the absence of both, even in the presence of eIF4G, did not allow TuMV infection (Nicaise et al., 2007). However, mutations could occur in the VPg of TuMV to overcome knockout mutants of either eIF(iso)4E or both eIF(iso)4G1 and eIF(iso)4G2, suggesting the presence of an eIF4F-independent pathway (Gallois et al., 2010).

The P3N-PIPO protein of TuMV (Fig. 1) was shown to interact with the Arabidopsis protein $\mathrm{PCaP} 1$, a cationbinding protein that attaches to the plasma membrane. In an Arabidopsis $P C a P 1$ knockout mutant (pcapl), TuMV was able to replicate but not able to move efficiently from cell to cell (Vijayapalani et al., 2012). Thus, pcapl is another potential candidate for a recessive mutant blocking infection of TuMV in other hosts.

Natural mutants of the Arabidopsis gene AtCA1, encoding a salicylic acid (SA) binding protein (SABP3), preventing the binding of SABP3 to the HC-Pro of TuMV (Fig. 1 ), could provide a candidate gene for enhancing plant defense, since the interaction between HC-Pro and SABP3 led to weakening of the SA-mediated defense response (Poque et al., 2018).

Other candidate resistance genes from Arabidopsis were described from the results of a genome-wide association study involving TuMV infection of 317 accessions of $A$. thaliana in the field in each of two years (Rubio et al., 2019), including: (1) Restricted TEV Movement 3 (RTM3; $A T 3 G 58350)$ at the end of chromosome 3 , involved in blocking long-distance movement (Cosson et al., 2010); (2) a QTL (AT3G01540) at the beginning of chromosome 3, encoding a DEAD Box RNA Helicase 1, shown to be involved in host-virus interactions, including TuMV ( $\mathrm{Li}$ et al., 2016b); (3) a QTL on chromosome 5 within the gene $A T 5 G 27640$, encoding a member of the eukaryotic translation initiation factor 3B; (4) a QTL on chromosome 2 , located in an intergenic region with one of the adjacent genes, $A T 2 G 30880$, encoding a protein with a pleckstrin homology domain involved in protein-protein interactions (Naughton et al., 2018); (5) a QTL at the end of chromosome 1 within the gene $A T 1 G 79470$, encoding a protein with a TIM-barrel domain, such as found in the protein 
encoded by the $T m-1$ gene that binds to the tomato mosaic virus replicase (Ishibashi et al., 2014); and (6) a QTL on chromosome 5, which overlaps with the gene AT5G18170 that encodes glutamate dehydrogenase 1 . These genes and others affected viral accumulation, maximum viral accumulation, and/or frequency of infected plants (Rubio et al., 2019).

\section{Non-conventional Resistance to TuMV}

Homologous viral-mediated resistance to TuMV. A number of studies have been done to determine whether sequences of TuMV expressed in transgenic plants could provide resistance to infection by TuMV. These include resistance established in model plants such as $N$. benthamiana or A. thaliana, as well as a few done using brassica crops. Resistance to TuMV infection to various degrees was observed in these studies, including: (1) the expression of the TuMV CP coding sequence in transgenic $N$. benthamiana, either alone (Jan et al., 1999) or together with a segment of the tomato spotted wilt virus encoding the $\mathrm{N}$ protein (Jan et al., 2000); (2) expression of the CP coding sequence in Arabidopsis (Nomura et al., 2004); (3) expression of artificial microRNAs (amiRNAs) with either TuMV sequences (HC-Pro or CP) alone, or TuMV HC-Pro plus turnip yellow mosaic virus sequences (from the coding region of the P69 movement protein) in Arabidopsis (Niu et al., 2006); (4) expression of artificial trans-acting small interfering RNAs against two viruses (TuMV and CMV) (Chen et al., 2016); (5) expression of TuMV CP, but not CP-mRNA in oilseed rape provided resistance (Lehmann et al., 2003); (6) expression of antisense of the TuMV NIb coding region in Chinese cabbage (Yu et al., 2007); and (7) expression of TuMV CP in Chinese cabbage (Li et al., 2014).

The studies involving the TuMV amiRNAs showed that the virus could mutate to break the amiRNA-mediated resistance, by either nucleotide mutation at the target site, or deletion of the target site, in the viral genome (Lin et al., 2009), and these mutations occurred in plants susceptible to TuMV (Lafforgue et al., 2011). Secondly, the effectiveness of amiRNA-mediated resistance could be improved by either using two amiRNAs with different targets (e.g., targeting HC-Pro and CP), or targeting highly conserved viral sequences (Lafforgue et al., 2013). As with some other situations involving resistance using the mechanism of RNA silencing, prior infection with unrelated viruses (especially CMV) can have a negative effect on maintaining amiRNAmediated resistance to TuMV in Arabidopsis (Martínez et al., 2013).
Other gene-mediated resistance to TuMV. Other approaches to obtaining resistance to infection by TuMV have been utilized, including: (1) the expression of trichosanthin (a ribosome-inactivating protein, which can inhibit virus infection) in transgenic tobacco inhibited TuMV infection (Lam et al., 1996); (2) overexpression of a singlechain variable fragment antibody, which contains ribonuclease activity (Lee et al., 2013), showed some degree of resistance to TuMV in transgenic Chinese cabbage plants, but methylation of the transgene led to loss of both expression and resistance (Zhao et al., 2013); (3) overexpression of Chinese cabbage eIF(iso)4E, modified in the capbinding pocket but still functional to support translation, in transgenic Chinese cabbage plants provided resistance to a broad-spectrum of TuMV strains (Kim et al., 2014); (4) overexpression of the soybean gene $G m S N 1$, encoding a snakin protein (related to potato snakin-1, an antimicrobial protein induced by gibberellic acid), in Arabidopsis, enhanced TuMV resistance (He et al., 2017); (5) the silencing of the $N$. benthamiana gene NbEXPA1, encoding an $\alpha$-expansin (a plasmodesmata-specific wall-loosening protein which interacts with the viral NIb protein), inhibited TuMV infection, but also plant growth (Park et al., 2017); (6) overexpression of the $N$. benthamiana gene $N b A L D 1$, encoding AGD2-like defense response protein 1 (shown previously to trigger defense against bacterial and fungal pathogens by regulating the SA pathway and an unknown SA-independent pathway), enhanced resistance to TuMV (Wang et al., 2019); (7) overexpression of the N. benthamiana gene HIR3.2, encoding the hypersensitive induced reaction protein 3.2 (part of the plant defense system against fungal and bacterial pathogens), enhanced resistance to TuMV in an SA- and EDS1-dependent pathway (Li et al., 2019b); and (8-10) three studies that utilized the CRISPRCas system to obtain resistance to infection by TuMV with CRISPR/Cas9 targeting the Arabidopsis eIF(iso)4E locus (Pyott et al., 2016), and CRISPR/Cas13a expressed to target TuMV sequences in either Arabidopsis (Aman et al., 2018b), or N. benthamiana plants (Aman et al., 2018a).

\section{Conclusions and Perspectives}

A number of resistance responses to infection have been identified and the genetics of most of these responses have been determined, mostly in Chinese cabbage and oilseed rape, but also in other Brassica species. From these, a selection of genes has been mapped and markers have been identified to facilitate the use of these genes in breeding for resistance. In a few cases, candidate genes for the 
resistance have been identified, and in rare instances, the candidate gene has been confirmed as the resistance gene. Still, many sources of resistance identified in various brassicas have neither been mapped nor further characterized, while resistance analysis in radish had largely remained unexplored, with only a few reports. While neither resistance to systemic infection nor extreme resistance has been reported in black mustard (B. nigra; BB genome), such resistance was identified in Ethiopian mustard (B. carinata; $\mathrm{BBCC}$ genome), and various subspecies of $B$. oleracea (CC genome). This suggests that contrary to some earlier speculation, the BB genome may also contain resistance genes, although no such genes have been identified or mapped. Nevertheless, there are numerous resistance responses that await mapping and identification, for either new resistance genes, or potential candidates identified for some of the genes already mapped in the same or other species. Isolating cloned dominant genes and transforming them into the genome of desirable cultivars of the same or related species should make the task of resistance breeding less onerous.

Arabidopsis was shown to contain several genes for resistance to TuMV, some of which have been cloned, while others represent possible candidate genes that could be explored for mapping and evaluation in syntenic crop species, such as brassicas or radish. The identification of genes expressing translation factors [eIF(iso)4E and others] in Arabidopsis, which confer recessive resistance to TuMV and other potyviruses has led to such genes being sought out as candidate resistance genes in various crops (reviewed by Shopan et al., 2020a, 2020b). In addition, various laboratories have developed novel forms of resistance against TuMV, by, intragenic (genes from related and sexually compatible species), cisgenic (genes from related but sexually incompatible species) or transgenic means; the last using expression of either TuMV sequences to induce RNA silencing, or other genes from various sources, usually in a model system, but also in brassica. While intragenics and cisgenics may come to be accepted by more countries, including for the expression of brassicid genes in other genera of the family, it does not appear that transgenic expression of unrelated genes will find their way into our crops in the near future, based on the costs involved in gaining approval; the latter of which moves at glacial speed. Therefore, it may be necessary to identify more sources of resistance as well as better characterize the many resistance responses already detected. Alternatively, various combinations of genes already identified in various Brassica spp. may be crossed into other cultivars of the same species. This will allow pyramiding of resistance genes, preventing infection by numerous pathotypes and obtain truly broad spectrum resistance. Several cultivars already contain more than one resistance gene, including: B. napus, line N-o-1 for TuRB01 and TuRB02; B. napus line S165 for TuBR04 and TuBR05; B. rapa line RLR22 for retr01 and (epistatic to) ConTR01; and B. rapa line AS9 for Rnt11 and $r n t 1-2$. In other cases, breeding and selection would have to be done for pyramiding such resistance genes.

\section{Conflicts of Interest}

No potential conflict of interest relevant to this article was reported.

\section{Acknowledgments}

This research was supported in part by a grant from the "Research Program for Agricultural Science \& Technology Development (Project NO. PJ01450102)", National Institute of Agricultural Sciences, Rural Development Administration (RDA), Republic of Korea, and a grant (Project No. PJ014501022020, "Development of TuMV resistance mass evaluation system and improvement of TuMV, and clubroot resistance molecular markers in Brassica vegetables") from the RDA, Republic of Korea.

\section{References}

Aman, R., Ali, Z., Butt, H., Mahas, A., Aljedaani, F., Khan, M. Z., Ding, S. and Mahfouz, M. 2018a. RNA virus interference via CRISPR/Cas13a system in plants. Genome Biol. 19:1.

Aman, R., Mahas, A., Butt, H., Ali, Z., Aljedaani, F. and Mahfouz, M. 2018b. Engineering RNA virus interference via the CRISPR/Cas13 machinery in Arabidopsis. Viruses 10:732.

Browning, K. S. 2004. Plant translation initiation factors: it is not easy to be green. Biochem. Soc. Trans. 32:589-591.

Chen, L., Cheng, X., Cai, J., Zhan, L., Wu, X., Liu, Q. and Wu, X. 2016. Multiple virus resistance using artificial trans-acting siRNAs. J. Virol. Methods 228:16-20.

Cheng, D. 2013. Cloning of turnip mosaic virus resistance related genes and development of trap marker in radish (Raphanus sativus L.). Ph.D. thesis. Nanjing Agricultural University, Nanjing, China.

Cheng, D., Zhang, F., Liu, L., Xu, L., Chen, Y., Wang, X., Limera, C., Yu, R. and Gong, Y. 2013. TRAP markers generated with resistance gene analog sequences and their application to genetic diversity analysis of radish germplasm. Sci. Hortic. 161:153-159.

Chung, B. Y.-W., Miller, W. A., Atkins, J. F. and Firth, A. E. 2008. An overlapping essential gene in the Potyviridae. Proc. Natl. Acad. Sci. U. S. A. 105:5897-5902. 
Chung, H., Jeong, Y.-M., Mun, J.-H., Lee, S.-S., Chung, W.-H. and $\mathrm{Yu}, \mathrm{H} .-\mathrm{J} .2014$. Construction of a genetic map based on high-throughput SNP genotyping and genetic mapping of a TuMV resistance locus in Brassica rapa. Mol. Genet. Genomics 289:149-160.

Cosson, P., Sofer, I., Le, Q. H., Léger, V., Schurdi-Levraud, V., Whitham, S. A., Yamamoto, M. L., Gopalan, S., Le Gall, O., Candresse, T., Carrington, J. C. and Rivers, F. 2010. RTM3, which controls long-distance movement of potyviruses, is a member of a new plant gene family encoding a meprin and TRAF homology domain-containing protein. Plant Physiol. 154:222-232.

Doucet, R., Shuttuck, V. I. and Stobbs, L. W. 1990. Rutabaga germplasm TuMV-R possessing resistance to turnip mosaic virus. HortScience 25:583-584.

Duprat, A., Caranta, C., Revers, F., Menand, B., Browning, K. S. and Robaglia, C. 2002. The Arabidopsis eukaryotic initiation factor (iso) $4 \mathrm{E}$ is depensable for plant growth but required for susceptibility to potyviruses. Plant J. 32:927-934.

Edwardson, J. R. and Christie, R. G. 1986. Turnip mosaic virus. In: Viruses infecting forage legumes, Vol. II, ed. by J. R. Edwardson, pp. 438-453. University of Florida, Gainesville, FL, USA.

Edwardson, J. R. and Christie, R. G. 1991. The potyvirus group. Florida Agricultural Experiment Station Monograph 16, Vol. I-IV. University of Florida, Gainesville, Florida, USA. 1244 pp.

Farzadfar, S. and Pourrahim, R. 2014. Characterization of Turnip mosaic virus from the Asian-BR population in Iran. J. Phytopathol. 162:824-828.

Farzadfar, S., Tomitaka, Y., Ikematsu, M., Golnaraghi, A. R., Pourrahim, R. and Ohshima, K. 2009. Molecular characterisation of Turnip mosaic virus isolates from Brassicaceae weeds. Eur. J. Plant Pathol. 124:45-55.

Fjellstrom, R. G. and Williams, P. H. 1997. Fusarium yellows and turnip mosaic virus resistance in Brassica rapa and B. juncea. HortScience 32:927-930.

Fujiwara, A., Inukai, T., Kim, B. M. and Masuta, C. 2011. Combinations of a host resistance gene and the CI gene of turnip mosaic virus differentially regulate symptom expression in Brassica rapa cultivars. Arch. Virol. 156:1575-1581.

Gallois, J.-L., Charron, C., Sánchez, F., Pagny, G., Houvenaghel, M.-C., Moretti, A., Ponz, F., Revers, F., Caranta, C. and German-Retana, S. 2010. Single amino acid changes in the turnip mosaic viral genome-linked protein (VPg) confer virulence towards Arabidopsis thaliana eIF(iso)4E and eIF(iso)4G. J. Gen. Virol. 91:288-293.

Gong, J., Ju, H.-K., Kim, I.-H., Seo, E.-Y., Cho, I.-S., Hu, W.-X., Han, J.-Y., Kim, J.-K., Choi, S. R., Lim, Y. P., Hammond, J. and Lim, H.-S. 2019. Sequence variations among 17 new radish isolates of Turnip mosaic virus showing differential pathogenicity and infectivity in Nicotiana benthamiana, Brassica rapa, and Raphanus sativus. Phytopathology 109:904-910.

Green, S. K. and Deng, T. C. 1985. Turnip mosaic virus strains in cruciferous hosts Taiwan. Plant Dis. 69:28-31.

Guerret, M. G. L., Nyalugwe, E. P., Maina, S., Barbetti, M. J., van Leur, J. A. G. and Jones, R. A. C. 2017. Biological and molecular properties of a Turnip mosaic virus (TuMV) strain that breaks TuMV resistances in Brassica napus. Plant Dis. 101:674-683.

Hagiwara-Komoda, Y., Choi, S. H., Sato, M., Atsumi, G., Abe J., Fukuda, J., Honjo, M. N., Nagano, A. J., Komoda, K., Nakahara, K. S., Uyeda, I. and Naito, S. 2016. Truncated yet functional viral protein produced via RNA polymerase slippage implies underestimated coding capacity of RNA viruses. Sci. Rep. 6:21411.

He, H., Yang, X., Xun, H., Lou, X., Li, S., Zhang, Z., Jiang, L., Dong, Y., Wang, S., Pang, J. and Liu, B. 2017. Over-expression of GmSN1 enhances virus resistance in Arabidopsis and soybean. Plant Cell Rep. 36:1441-1455.

Hu, W.-X., Seo., E.-Y., Cho, I.-S., Kim, J.-K., Ju, H.-K., Kim, I.H., Choi, G.-W., Kim, B., Ahn, C.-H., Domier, L. L., Oh, S.K., Hammond, J. and Lim, H.-S. 2019. Amino acid differences in the N-terminal half of the polyproteins of Chinese turnip mosaic virus isolates affect symptom expression in Nicotiana benthamiana and radish. Arch. Virol. 164:1683-1689.

Hughes, S. L., Hunter, P. J., Sharpe, A. G., Kearsey, M. J., Lydiate, D. J. and Walsh, J. A. 2003. Genetic mapping of the novel Turnip mosaic virus resistance gene TuRB03 in Brassica napus. Theor. Appl. Genet. 107:1169-1173.

Ishibashi, K., Kezuka, Y., Kobayashi, C., Kato, M, Inoue, T., Nonaka, T., Ishikawa, M., Matsumura, H. and Katoh, E. 2014. Structural basis for the recognition-evasion arms race between Tomato mosaic virus and the resistance gene Tm-1. Proc. Natl. Acad. Sci. U. S. A. 111:E3486-E3495.

Jan, F.-J., Fagoaga, C., Pang, S.-Z. and Gonsalves, D. 2000. A single chimeric transgene derived from two distinct viruses confers multi-virus resistance in transgenic plants through homology-dependent gene silencing. J. Gen. Virol. 81:21032109.

Jan, F.-J., Pang, S.-Z., Fagoaga, C. and Gonsalves, D. 1999. Turnip mosaic potyvirus resistance in Nicotiana benthamiana derived by post-transcriptional gene silencing. Transgenic Res. 8:203-213.

Jenner, C. E., Nellist, C. F., Barker, G. C. and Walsh, J. A. 2010. Turnip mosaic virus (TuMV) is able to use alleles of both eIF4E and $e I F$ (iso) $4 E$ from multiple loci of the diploid Brassica rapa. Mol. Plant-Microbe Interact. 23:1498-1505.

Jenner, C. E., Sánchez, F., Nettleship, S. B., Foster, G. D., Ponz, F. and Walsh, J. A. 2000. The cylindrical inclusion gene of Turnip mosaic virus encodes a pathogenic determinant to the brassica resistance gene TuRBO1. Mol. Plant-Microbe Interact. 13:1102-1108.

Jenner, C. E., Tomimura, K., Ohshima, K., Hughes, S. L. and Walsh, J. A. 2002. Mutations in Turnip mosaic virus P3 and cylindrical inclusion proteins are separately required to overcome two Brassica napus resistance genes. Virology 300:5059. 
Jenner, C. E. and Walsh, J. A. 1996. Pathogenic variation in turnip mosaic virus with special reference to European isolates. Plant Pathol. 45:848-856.

Jenner, C. E., Wang, X., Tomimura, K., Ohshima, K., Ponz, F. and Walsh, J. A. 2003. The dual role of the potyvirus P3 protein of Turnip mosaic virus as a symptom and avirulence determinant in brassicas. Mol. Plant-Microbe Interact. 16:777784.

Jennings, M. D. and Pavitt, G. D. 2014. A new function and complexity for protein translation initiation factor eIF2B. Cell Cycle 13:2660-2665.

Jin, M., Lee, S.-S., Ke, L., Kim, J. S., Seo, M.-S., Sohn, S.-H., Park, B.-S. and Bonnema, G. 2014. Identification and mapping of a novel dominant resistant gene, TuRB07 to Turnip mosaic virus in Brassica rapa. Theor. Appl. Genet. 127:509519.

Kaneko, Y., Natsuaki, T., Bang, S. W. and Matsuzawa, Y. 1996. Identification and evaluation of turnip mosaic virus (TuMV) resistance gene in kale monosomic addition lines of radish. Jpn. J. Breed. 46:117-124.

Kaneko, Y.-H., Inukai, T., Suehiro, N., Natsuaki, T. and Masuta, C. 2004. Fine genetic mapping of the TuNI locus causing systemic veinal necrosis by turnip mosaic virus infection in Arabidopsis thaliana. Theor. Appl. Genet. 110:33-40.

Kehoe, M. A., Coutts, B. A. and Jones, R. A. C. 2010. Resistance phenotypes in diverse accessions, breeding lines, and cultivars of three mustard species inoculated with Turnip mosaic virus. Plant Dis. 94:1290-1298.

Kim, B., Masuta, C., Matsuura, H., Takahashi, H. and Inukai, T. 2008. Veinal necrosis induced by Turnip mosaic virus infection in Arabidopsis is a form of defense response accompanying HR-like cell death. Mol. Plant-Microbe Interact. 21:260268.

Kim, B. M., Suehiro, N., Natsuaki, T., Inukai., T. and Masuta, C. 2010. The P3 protein of Turnip mosaic virus can alone induce hypersensitive response-like cell death in Arabidopsis thaliana carrying TuNI. Mol. Plant-Microbe Interact. 23:144-152.

Kim, I.-H., Ju, H.-K., Gong, J., Han, J.-Y., Seo, E.-Y., Cho, S.-W., Hu, W.-X., Choi, S. R., Lim, Y. P., Domier, L. L., Hammond, J. and Lim, H.-S. 2019. A turnip mosaic virus determinant of systemic necrosis in Nicotiana benthamiana and a novel resistance-breaking determinant in Chinese cabbage identified from chimeric infectious clones. Phytopathology 109:16381647.

Kim, J., Kang, W.-H., Hwang, J., Yang, H.-B., Kim, D., Oh, C.-S. and Kang, B.-C. 2014. Transgenic Brassica rapa plants overexpressing eIF(iso)4E variants show broad-spectrum Turnip mosaic virus (TuMV) resistance. Mol. Plant Pathol. 15:615626.

Kim, J., Kang, W.-H., Yang, H.-B., Park, S., Jang, C.-S., Yu, H.J. and Kang, B.-C. 2013. Identification of a broad-spectrum recessive gene in Brassica rapa and molecular analysis of the eIF4E gene family to develop molecular markers. Mol. Breed. 32:385-398.
Kitashiba, H., Li, F., Hirakawa, H., Kawanabe, T., Zou, Z., Hasegawa, Y., Tonosaki, K., Shirasawa, S., Fukushima, A., Yokoi, S., Takahata, Y., Kakizaki, T., Ishida, M., Okamoto, S., Sakamoto, K., Shirasawa, K., Tabata, S. and Mishio, T. 2014. Draft sequence of the radish (Raphanus sativus L.) genome. DNA Res. 21:481-490.

Korkmaz, S., Cevik, B., Karanfil, A., Onder, S. and Ohshima, K. 2020. Phylogenetic relationships and genetic structure of populations of turnip mosaic virus in Turkey. Eur. J. Plant Pathol. 156:559-569.

Korkmaz, S., Tomitaka, Y., Onder, S. and Ohshima, K. 2008. Occurrence and molecular characterization of Turkish isolates of Turnip mosaic virus. Plant Pathol. 57:1155-1162.

Lafforgue, G., Martínez, F., Niu, Q.-W., Chua, N.-H., Daròs, J.A. and Elena, S. F. 2013. Improving the effectiveness of artificial microRNA (amiR)-mediated resistance against Turnip mosaic virus by combining two amiRs or by targeting highly conserved viral genomic regions. J. Virol. 87:8254-8256.

Lafforgue, G., Martínez, F., Sardanyés, J., de la Iglesia, F., Niu, Q.-W., Lin, S.-S., Solé, R.V., Chua, N.-H., Daròs, J.-A. and Elena, S. F. 2011. Tempo and mode of plant RNA virus escape from RNA interference-mediated resistance. J. Virol. 85:9686-9695.

Lam, Y.-H., Wong, Y.-S., Wang, B., Wong, R. N.-S., Yeung, H.-W. and Shaw, P.-C. 1996. Use of trichosanthin to reduce infection by turnip mosaic virus. Plant Sci. 114:111-117.

Lee, G., Shim, H.-K., Kwon, M.-H., Son, S.-H., Kim, K.-Y., Park, E.-Y., Yang, J.-K., Lee, T.-K., Auh, C.-K., Kim. D., Kim, Y.S. and Lee, S. 2013. RNA virus accumulation is inhibited by ribonuclease activity of 3D8 scFv in transgenic Nicotiana tabacum. Plant Cell Tissue Organ Cult. 115:189-197.

Lehmann, P., Jenner, C. E., Kozubek, E., Greenland, A. J. and Walsh, J. A. 2003. Coat protein-mediated resistance to Turnip mosaic virus in oilseed rape (Brassica napus). Mol. Breed. 11:83-94.

Lehmann, P., Petrzik, K., Jenner, C., Greenland, A., Špak, J., Kozubek, E. and Walsh, J. A. 1997. Nucleotide and amino acid variation in the coat protein coding region of turnip mosaic virus isolates and possible involvement in the interaction with the brassica resistance gene TuRB01. Physiol. Mol. Plant Pathol. 51:195-208.

Lellis, A. D., Kasschau, K. D., Whitham, S. A. and Carrington, J. C. 2002. Loss-of-susceptibility mutants of Arabidopsis thaliana reveal an essential role of $\mathrm{eIF}$ (iso)4E during potyvirus infection. Curr. Biol. 12:1046-1051.

Li, G., Lv, H., Zhang, S., Zhang, S., Li, F., Zhang H., Qian, W., Fang, Z. and Sun, R. 2019a. TuMV management for brassica crops through host resistance: retrospect and prospects. Plant Pathol. 68:1035-1044.

Li, G.-L., Qian, W., Zhang, S.-J., Zhang, S.-F., Li, F., Zhang, H., Wu, J., Wang, X.-W. and Sun, R.-F. 2016a. Development of gene-based markers for the Turnip mosaic virus resistance gene retr02 in Brassica rapa. Plant Breed. 135:466-470.

Li, H. S. 2009. Genetic dissection of resistance to turnip mosaic 
virus and black rot in radish (Raphanus sativus L.). Ph.D. thesis. Chinese Academy of Agricultural Sciences, Beijing, China.

Li, Q., Zhang, Z., Liu, S., Lu, J. and Zhao, Z. 2012. Inheritance analysis of Turnip mosaic virus resistance in Chinese cabbage. Acta Agric. Boreal. Sin. 27:135-139 (in Chinese).

Li, Q., Zhang, X., Zheng, Q., Zhang, Z., Liu, S., Pei, Y., Wang, S., Liu, X., Xu, W., Fu, W., Zhao, Z. and Song, X. 2015. Identification and mapping of a novel Turnip mosaic virus resistance gene TuRBCS01 in Chinese cabbage (Brassica rapa L.). Plant Breed. 134:221-225.

Li, S., Zhao, J., Zhai, Y., Yuan, Q., Zhang, H., Wu, X., Lu, Y., Peng, J., Sun, Z., Lin, L., Zheng, H., Chen, J. and Yan, F. 2019b. The hypersensitive induced reaction 3 (HIR3) gene contributes to plant basal resistance via an EDS1 and salicylic acid-dependent pathway. Plant J. 98:783-797.

Li, W. H., Yu, G., Lei, Y., Chong, S. C. and Shu, P. Q. 2014. Coat protein-mediated resistance to Turnip mosaic virus in Chinese cabbage (Brassica rapa ssp. pekinensis) by the pollen-tube method. Int. J. Agric. Biol. 16:6.

Li, Y., Xiong, R., Bernards, M. and Wang, A. 2016b. Recruitment of Arabidopsis RNA helicase AtRH9 to the viral replication complex by viral replicase to promote Turnip mosaic virus replication. Sci. Rep. 6:30297.

Lin, S.-S., Wu, H.-W., Elena, S. F., Chen, K.-C., Niu, Q.-W., Yeh, S.-D., Chen, C.-C. and Chua, N.-H. 2009. Molecular evolution of a viral non-coding sequence under the selective pressure of amiRNA-mediated silencing. PLoS Pathog. 5:e1000312.

Liu, J., Kim, B. M., Kaneko, Y.-H., Inukai, T. and Masuta, C. 2015. Identification of the TuNI gene causing systemic necrosis in Arabidopsis ecotype Ler infected with Turnip mosaic virus and characterization of its expression. J. Gen. Plant Pathol. 81:180-191.

Liu, X., Lu, W., Liu, Y. and Li, J. 1990. A study of TuMV differentiation on cruciferous vegetables from ten provinces in China: a new host differentiator screening and strain classification. Chin. Sci. Bull. 35:1734-1739.

Liu, X. P., Lu, W. C., Liu, Y. K., Wei, S. Q., Xu, J. B., Liu, J. B., Liu, Z. R., Zhang, H. J., Li, J. L., Ke, G. L., Yao, W. Y., Cai, Y. S., Wu, F. Y., Cao, S. C., Li, Y. H., Xie, S. D., Lin, B. X. and Zhang, C. L. 1996. Occurrence and strain differentiation of turnip mosaic potyvirus and sources of resistance in Chinese cabbage in China. Acta Hortic. 407:431-440.

López-González, S., Aragonés, V., Daròs, J.-A., Sánchez, F. and Ponz, F. 2017. An infectious cDNA clone of a radish-infecting Turnip mosaic virus strain. Eur. J. Plant Pathol. 148:207211.

Lv, S., Z., C., Tang, J., Li, Y., Wang, Z., Jiang, D. and Hou, X. 2015. Genome-wide analysis and identification of TIR-NBSLRR genes in Chinese cabbage (Brassica rapa ssp. pekinensis) reveal expression patterns to TuMV infection. Physiol. Mol. Plant Pathol. 90:89-97.

Lydiate, D. J., Rusholme Pilcher, R. L., Higgins, E. E. and Walsh,
J. A. 2014. Genetic control of immunity to Turnip mosaic virus (TuMV) pathotype 1 in Brassica rapa (Chinese cabbage). Genome 57:419-425.

Ma, J., Hou, X., Xiao, D., Qi, L., Wang, F., Sun, F. and Wang, Q. 2010. Cloning and characterization of the BcTuR3 gene related to resistance to turnip mosaic virus (TuMV) from nonheading Chinese cabbage. Plant Mol. Biol. Rep. 28:588-596.

Marcotrigiano, J., Gingras, A.-C., Sonenberg, N. and Burley, S. K. 1999. Cap-independent translation initiation in eukaryotes is regulated by a molecular mimic of eIF4G. Mol. Cell 3:707716.

Martínez, F., Elena, S. F. and Daròs, J.-A. 2013. Fate of artificial microRNA-mediated resistance to plant viruses in mixed infections. Phytopathology 103:870-876.

Martín Martín, A., Cabrera y Poch, H. L., Martínez-Herrera, D. and Ponz, F. 1999. Resistance to turnip mosaic potyvirus in Arabidopsis thaliana. Mol. Plant-Microbe Interact. 12:10161021.

Montesclaros, L., Nicol, N., Ubalijoro, E., Leclerc-Potvin, C., Ganivet, L., Laliberté, J.-F. and Fortin, M. G. 1997. Response to potyvirus infection and genetic mapping of resistance loci to potyvirus infection in Lactuca. Theor. Appl. Genet. 94:941946.

Naughton, F. B., Kalli, A. C. and Sansom, M. S. P. 2018. Modes of interaction of pleckstrin homology domains with membranes: toward a computational biochemistry of membrane recognition. J. Mol. Biol. 430:372-388.

Nellist, C. F., Qian, W., Jenner, C. E., Moore, J. D., Zhang, S., Wang, X., Briggs, W. H., Barker, G. C., Sun, R. and Walsh, J. A. 2014. Multiple copies of eukaryotic translation initiation factors in Brassica rapa facilitate redundancy, enabling diversification through variation in splicing and broad-spectrum resistance. Plant J. 77:261-268.

Nguyen, H. D., Tomitaka, Y., Ho, S. Y. W., Duchêne, S., Vetten, H.-J., Lesemann, D., Walsh, J. A., Gibbs, A. J. and Ohshima, K. 2013a. Turnip mosaic potyvirus probably first spread to Eurasian brassica crops from wild orchids about 1000 years ago. PLoS ONE 8:e55336.

Nguyen, H. D., Tran, H. T. N. and Ohshima, K. 2013b. Genetic variation of the Turnip mosaic virus population of Vietnam: a case study of founder, regional and local influences. Virus Res. 171:138-149.

Nicaise, V., Gallois, J.-L., Chafiai, F., Allen, L. M., SchurdiLevaud, V., Browning, K. S., Candresse, T., Caranta, C., Le Gall, O. and German-Retana, S. 2007. Coordinated and selective recruitment of eIF4E and eIF4G factors for potyvirus infection in Arabidopsis thaliana. FEBS Lett. 581:1041-1046.

Nicolas, O. and Laliberté, J.-F. 1992. The complete nucleotide sequence of turnip mosaic potyvirus RNA. J. Gen. Virol. 73:2785-2793.

Niu, Q.-W., Lin, S.-S., Reyes, J. L., Chen, K.-C., Wu, H.-W., Yeh, S.-D. and Chua, N.-H. 2006. Expression of artificial microRNAs in transgenic Arabidopsis thaliana confers virus resistance. Nat. Biotechnol. 24:1420-1428. 
Nomura, K., Ohshima, K., Anai, T., Uekusa, H. and Kita, N. 2004. RNA silencing of the introduced coat protein gene of Turnip mosaic virus confers broad-spectrum resistance in transgenic Arabidopsis. Phytopathology 94:730-736.

Nyalugwe, E. P., Barbetti, M. J. and Jones, R. A. C. 2014. Preliminary studies on resistance phenotypes to Turnip mosaic virus in Brassica napus and B. carinata from different continents and effects of temperature on their expression. Eur. J. Plant Pathol. 139:687-706.

Nyalugwe, E. P., Barbetti, M. J. and Jones, R. A. C. 2015a. Studies on resistance phenotypes to Turnip mosaic virus in five species of Brassicaceae, and identification of a virus resistance gene in Brassica juncea. Eur. J. Plant Pathol. 141:647666.

Nyalugwe, E. P., Jones, R. A. C., Barbetti, M. J. and Kehoe, M. A. 2015b. Biological and molecular variation amongst Australian Turnip mosaic virus isolates. Plant Pathol. 64:12151223.

Nyalugwe, E. P., Barbetti, M. J. and Jones, R. A. C. 2016. Strain specificities on Turnip mosaic virus resistance gene TuRBJU01 in Brassica juncea. Eur. J. Plant Pathol. 145:209-213.

Ohshima, K., Yamaguchi, Y., Hirota, R., Hamamota, T., Tomimura, K., Tan, Z., Sano, T., Azuhata, F., Walsh, J. A., Fletcher, J., Chen, J., Gera, A. and Gibbs, A. 2002. Molecular evolution of Turnip mosaic virus: evidence of host adaptation, genetic recombination and geographical spread. J. Gen. Virol. 83:15111521.

Olspert, A., Chung, B. Y.-W., Atkins, J. F., Carr, J. P. and Firth, A. E. 2015. Transcriptional slippage in the positive-sense RNA virus family Potyviridae. EMBO Rep. 16:995-1004.

Park, S.-H., Li, F., Renaud, J., Shen, W., Li, Y., Guo, L., Cui, H., Sumarah, M. and Wang, A. 2017. NbEXPA1, an $\alpha$-expansin, is plasmodesmata-specific and a novel host factor for potyviral infection. Plant J. 92:846-861.

Parmar, N., Thakur, A. K., Kumar, P., Thakur, P. D. and Bhardwaj, S. V. 2017. Molecular characterization of Turnip mosaic potyvirus (TuMV)-infecting radish (Raphanus sativus L.) crop in India. 3 Biotech 7:382.

Pink, D. A. C., Sutherland, R. A. and Walkey, D. G. A. 1986. Genetic analysis of resistance in Brussels sprout to cauliflower mosaic and turnip mosaic viruses. Ann. Appl. Biol. 109:199208.

Poque, S., Wu, H.-W., Huang, C.-H., Cheng, H.-W., Hu, W.-C., Yang, J.-Y., Wang, D. and Yeh, S.-D. 2018. Potyviral genesilencing suppressor HCPro interacts with salicylic acid (SA)binding protein 3 to weaken SA-mediated defense responses. Mol. Plant-Microbe Interact. 31:86-100.

Pound, G. S. 1948. Horseradish mosaic. J. Agric. Res. 77:97-114.

Pound, G. S. and Walker, J. C. 1945. Differentiation of certain crucifer viruses by the use of temperature and host immunity reactions. J. Agric. Res. 71:255-278.

Provvidenti, R. 1980. Evaluation of Chinese cabbage cultivars from Japan and the People's Republic of China for resistance to turnip mosaic virus and cauliflower mosaic virus. J. Am.
Soc. Hortic. Sci. 105:571-573.

Pyott, D. E., Sheehan, E. and Molnar, A. 2016. Engineering of CRISPR/Cas9-mediated potyvirus resistance in transgenefree Arabidopsis plants. Mol. Plant Pathol. 17:1276-1288.

Qian, W., Zhang, S., Zhang, S., Li, F., Zhang, H., Wu, J., Wang, X., Walsh, J. A. and Sun, R. 2013. Mapping and candidate-gene screening of the novel Turnip mosaic virus resistance gene retr02 in Chinese cabbage (Brassica rapa L.). Theor. Appl. Genet. 126:179-188.

Revers, F. and García, J. A. 2015. Molecular biology of potyviruses. Adv. Virus Res. 92:101-199.

Robbins, M. A., Witsenboer, H., Michelmore, R. W., Laliberte, J.-F. and Fortin, M. G. 1994. Genetic mapping of turnip mosaic virus resistance in Lactuca sativa. Theor. Appl. Genet. 89:583-589.

Rodamilans, B., Valli, A., Mingot, A., San León, D., Baulcombe, D., López-Moya, J. J. and García, J. A. 2015. RNA polymerase slippage as a mechanism for the production of frameshift gene products in plants viruses of the Potyviridae family. J. Virol. 89:6965-6967.

Rubio, B., Cosson, P., Caballero, M., Revers, F., Bergelson, J., Roux, F. and Schurdi-Levraud, V. 2019. Genome-wide association study reveals new loci involved in Arabidopsis thaliana and Turnip mosaic virus (TuMV) interactions in the field. New Phytol. 221:2026-2038.

Rusholme, R. L., Higgins, E. E., Walsh, J. A. and Lydiate, D. J. 2007. Genetic control of broad-spectrum resistance to turnip mosaic virus in Brassica rapa (Chinese cabbage). J. Gen. Virol. 88:3177-3186.

Sako, N. 1981. Virus disease of Chinese cabbage in Japan. In: Chinese cabbage. Proceedings of the First International Symposium, eds. by N. S. Talekar and T. D. Griggs, pp. 129-141. AVRDC, Shanhau, Tawain.

Sánchez, F., Wang, X., Jenner, C. E., Walsh, J. A. and Ponz, F. 2003. Strains of Turnip mosaic potyvirus as defined by the molecular analysis of the coat protein gene of the virus. Virus Res. 94:33-43.

Sardaru, P., Sinausía, L., López-González, S., Zindovic, J., Sánchez, F. and Ponz, F. 2018. The apparent non-host resistance of Ethiopian mustard to a radish-infecting strain of Turnip mosaic virus is largely determined by the C-terminal region of the P3 viral protein. Mol. Plant Pathol. 19:1984-1994.

Sato, M., Nakahara, K., Yoshii, M., Ishikawa, M. and Uyeda, I. 2005. Selective involvement of the eukaryotic initiation factor $4 \mathrm{E}$ family in the infection of Arabidopsis thaliana by potyviruses. FEBS Lett. 579:1167-1171.

Sevik, M. A. and Deligoz, I. 2016. The reaction of cabbage (Brassica oleracea L.) breeding lines against Turnip mosaic virus. Acta Sci. Pol. Hortorum Cultus 15:111-119.

Shattuck, V. I. 1992. UG1 turnip germplasm possessing resistance to turnip mosaic virus. HortScience 27:938-939.

Shattuck, V. I. and Stobbs, L. W. 1987. Evaluation of rutabaga cultivars for turnip mosaic virus resistance and inheritance of resistance. HortScience 22:935-937. 
Shopan, J., Mou, H., Zhang, L., Zhang, C., Ma, W., Walsh, J. A., $\mathrm{Hu}$, Z., Yang, J. and Zhang, M. 2017. Eukaryotic translation initiation factor $2 B$-beta (eIF2B $\beta$ ), a new class of plant virus resistance gene. Plant J. 90:929-940.

Shopan, J., Liu, C., Hu, Z., Zhang, M. and Yang, J. 2020a. Identification of eukaryotic initiation factors and the temperaturedependent nature of Turnip mosaic virus epidemics in allopolyploid Brassica juncea. 3 Biotech 10:75.

Shopan, J., Lv, X., Hu, Z., Zhang, M. and Yang, J. 2020b. Eukaryotic translation initiation factors shape RNA viruses resistance in plants. Hortic. Plant J. 6:81-88.

Stobbs, L. W. and Shuttuck, V. I. 1989. Turnip mosaic virus strains in southern Ontario, Canada. Plant Dis. 73:208-212.

Suehiro, N., Natsuaki, T., Watanabe, T. and Okuda, S. 2004. An important determinant of the ability of Turnip mosaic virus to infect Brassica spp. and/or Raphanus sativus is in its $\mathrm{P} 3$ protein. J. Gen. Virol. 85:2087-2098.

Suh, S. K., Green, S. K. and Park, H. G. 1995. Genetic resistance to five strains of turnip mosaic virus in Chinese cabbage. Euphytica 81:71-77.

Tomimura, K., Gibbs, A. J., Jenner, C. E., Walsh, J. A. and Ohshima, K. 2003. The phylogeny of Turnip mosaic virus: comparisons of 38 genomic sequences reveal a Eurasian origin and a recent 'emergence' in east Asia. Mol. Ecol. 12:2099-2111.

Tomimura, K., Špak, J., Katis, N., Jenner, C. E., Walsh, J. A., Gibbs, A. J. and Ohshima, K. 2004. Comparisons of the genetic structure of populations of Turnip mosaic virus in West and East Eurasia. Virology 330:408-423.

Tomitaka, Y. and Ohshima, K. 2006. A phylogeographical study of the Turnip mosaic virus population in East Asia reveals an 'emergent' lineage in Japan. Mol. Ecol. 15:4437-4457.

Tomlinson, J. A. 1987. Epidemiology and control of virus diseases of vegetables. Ann. Appl. Biol. 110:661-681.

Tomlinson, J. A. and Ward, C. M. 1981. The reactions of some Brussels sprout $\mathrm{F}_{1}$ hybrids and inbreds to cauliflower mosaic and turnip mosaic viruses. Ann. Appl. Biol. 97:205-212.

Vijayapalani, P., Maeshima, M., Nagasaki-Takekuchi, N. and Miller, W. A. 2012. Interaction of the trans-frame potyvirus protein P3N-PIPO with the host protein PCaP1 facilitates potyvirus movement. PLoS Pathog. 8:e1002639.

Walkey, D. G. A. and Neely, H. A. 1980. Resistance in white cabbage to necrosis caused by turnip and cauliflower mosaic viruses and pepper-spot. J. Agric. Sci. 95:703-713.

Walkey, D. G. A. and Pink, D. A. C. 1988. Reaction of white cabbage (Brassica oleracea var. capitata) to four different strains of turnip mosaic virus. Ann. Appl. Biol. 112:273-284.

Walsh, J. A. 1989. Genetic control of immunity to turnip mosaic virus in winter oilseed rape (Brassica napus spp. oleifera) and the effects of foreign isolates of the virus. Ann. Appl. Biol. 115:89-99.

Walsh, J. A. and Jenner, C. E. 2002. Turnip mosaic virus and the quest for durable resistance. Mol. Plant Pathol. 3:289-300.

Walsh, J. A. and Jenner, C. E. 2006. Resistance to Turnip mosaic virus in the Brassicaceae. In: Natural resistance mechanisms of plants to viruses, eds. by G. Loebenstein and J. P. Carr, pp. 425-430. Springer, Dordrecht, The Netherlands.

Walsh, J. A., Rusholme, R. L., Hughes, S. L., Jenner, C. E., Bambridge, J. M., Lydiate, D. J. and Green, S. K. 2002. Different classes of resistance to turnip mosaic virus in Brassica rapa. Eur. J. Plant Pathol. 108:15-20.

Walsh, J. A., Sharpe, A. G., Jenner, C. E. and Lydiate, D. J. 1999. Characterisation of resistance to turnip mosaic virus in oilseed rape (Brassica napus) and genetic mapping of TuRB01. Theor. Appl. Genet. 99:1149-1154.

Wang, H.-Y., Liu J.-L., Gao, R., Chen, J., Shao, Y.-H. and Li, X.-D. 2009a. Complete genomic sequence analysis of Turnip mosaic virus basal-BR isolates from China. Virus Genes 38:421428.

Wang, S., Han, K., Peng, J., Zhao, J., Jiang, L., Lu, Y., Zheng, H., Lin, L., Chen, J. and Yan, F. 2019. NbALD1 mediates resistance to turnip mosaic virus by regulating the accumulation of salicylic acid and the ethylene pathway in Nicotiana benthamiana. Mol. Plant Pathol. 20:990-1004.

Wang, X., Chen, H., Zhu, Y. and Hou, R. 2009b. An AFLP marker to turnip mosaic virus resistance gene in pak-choi. Afr. $J$. Biotechnol. 8:2508-2512.

Wei, T., Zhang, C., Hou, X., Sanfaçon, H. and Wang, A. 2013. The SNARE protein Syp71 is essential for turnip mosaic virus infection by mediating fusion of virus-induced vesicles with chloroplasts. PLoS Pathog. 9:e1003378.

Wittmann, S., Chatel, H., Fortin, M. G. and Laliberté, J. F. 1997. Interaction of the viral protein genome linked of turnip mosaic potyvirus with the translation eukaryotic initiation factor (iso) 4E of Arabidopsis thaliana using the yeast two-hybrid system. Virology 234:84-92.

Xinhua, W., Yang, L. and Houying, C. 2011. A linkage map of pak-choi (Brassica rapa ssp. chinensis) based on AFLP and SSR markers and identification of AFLP markers for resistance to TuMV. Plant Breed. 130:275-277. [Note, the authors names on this paper were incorrectly published. They actually should be Wang, X(H)., Li Y. and Chen, H(Y)., as identified in the review by Li et al., 2019a.]

Yasaka, R., Fukagawa, H., Ikematsu, M., Soda, H., Korkmaz, S., Golnaraghi, A., Katis, N., Ho, S. Y. W., Gibbs, A. J. and Ohshima, K. 2017. The timescale of emergence and spread of turnip mosaic virus. Sci. Rep. 7:4240.

Yoon, J. Y., Green, S. K. and Opeña, R. T. 1993. Inheritance of resistance to turnip mosaic virus in Chinese cabbage. Euphytica 69:103-108.

Yoshii, H. 1963. On the strain distribution of turnip mosaic virus. Ann. Phytopathol. Soc. Jpn. 28:221-227.

Yu, H.-J., Jeong, Y.-M. and Mun, J.-H. 2017a. Comparative analysis of the radish genome with Brassica genomes. In: The radish genome, compendium of plant genomes, eds. by T. Nishio and H. Kitashiba, pp. 53-69. Springer International Publishing AG, Cham, Switzerland.

Yu, X., Choi, S. R. and Lim, Y. P. 2017b. Molecular mapping of disease resistance genes. In: The radish genome, compendium 
of plant genomes, eds. by T. Nishio and H. Kitashiba, pp. 165-175. Springer International Publishing AG, Cham, Switzerland.

Yu, Z., Zhao, S. and He, Q. 2007. High level resistance to Turnip mosaic virus in Chinese cabbage (Brassica campestris ssp. Pekinensis (Lour) Olsson) transformed with the antisense NIb gene using marker-free Agrobacterium tumefaciens infiltration. Plant Sci. 172:920-929.

Zhang, C., Lyu, S., Gao, L., Song, X., Li, Y. and Hou, X. 2018. Genome-wide identification, classification, and expression analysis of SNARE genes in Chinese cabbage (Brassica rapa ssp. pekinensis) infected by Turnip mosaic virus. Plant Mol. Biol. Rep. 36:210-224.

Zhang, F. L., Wang, M., Liu, X. C., Zhao, X. Y. and Yang, J. P. 2008a. Quantitative trait loci analysis for resistance against Turnip mosaic virus based on a double-haploid population in
Chinese cabbage. Plant Breed. 127:82-86.

Zhang, J.-H., Qu, S.-P. and Cui, C.-S. 2008b. Analysis of QTL for Turnip mosaic virus resistance in Chinese cabbage. Acta Phytopathol. Sin. 38:178-184.

Zhang, X.-W., Yuan, Y.-X., Wang, X.-W., Sun, R.-F., Wu, J., Xie, C.-H., Jang, W.-S. and Yao, Q.-J. 2009. QTL mapping for TuMV resistance in Chinese cabbage [Brassica campestris L. ssp. pekinensis (Lour.) Olssom]. Acta Hortic. Sin. 36:731736.

Zhao, M.-A., An, S.-J., Lee, S.-C., Kim, D.-S. and Kang, B.-C. 2013. Overexpression of a single-chain variable fragment $(s c F v)$ antibody confers unstable resistance to TuMV in Chinese cabbage. Plant Mol. Biol. Rep. 31:1203-1211.

Zink, F. W. and Duffus, J. E. 1970. Linkage of turnip mosaic virus susceptibility and downy mildew (Bremia lactucae) in lettuce. J. Am. Soc. Hortic. Sci. 95:420-422. 